Original Research Paper

\title{
Some Aspects of the Human Body's Hydraulics
}

\author{
${ }^{1}$ Relly Victoria Virgil Petrescu, ${ }^{2}$ Raffaella Aversa, ${ }^{2}$ Antonio Apicella and ${ }^{1}$ Florian Ion Tiberiu Petrescu \\ ${ }^{1}$ IFToMM, ARoTMM, Bucharest Polytechnic University, Bucharest, Romania \\ ${ }^{2}$ Advanced Materials Lab, Department of Architecture and Industrial Design, Second University of Naples, Aversa, Italy
}

\author{
Article history \\ Received: 13-03-2019 \\ Revised: 15-07-2019 \\ Accepted: 08-08-2019 \\ Corresponding Author: \\ Florian Ion Tiberiu Petrescu \\ Bucharest Polytechnic \\ University, Bucharest, \\ Romania \\ Email: fitpetrescu@gmail.com
}

\begin{abstract}
This paper presents some aspects related to the human body's hydraulics in the desire to make readers aware of how to maintain all the blood vessels of the human body in order to maintain the entire healthy, functional, young, vigorous circulatory system for a while the longest possible. The problem is complex because it has to be viewed from all points of view and not only as an isolated system in the body, having aspects of feedback on the whole physiopathology belonging to the human body. The highly circulating system needs permanent maintenance. Self-maintenance is done through various physiological mechanisms tightly linked to each other, including the lymphatic, digestive, renal, lung, nervous, glandular system ... It is not possible to completely separate the physiology of a system from the other adjacent systems because they all work synergistically, being permanently controlled by the central and peripheral nervous system.
\end{abstract}

Keywords: Human Body, Human Body's Hydraulics, Blood Vessels, Physiopathology, Anti-Aging, Biotechnology, Bioengineering

\section{Introduction}

This paper presents some aspects related to the human body's hydraulics in the desire to make readers aware of how to maintain all the blood vessels of the human body in order to maintain the entire healthy, functional, young, vigorous circulatory system for a while the longest possible.

The problem is complex because it has to be viewed from all points of view and not only as an isolated system in the body, having aspects of feedback on the whole physiopathology belonging to the human body.

The highly circulating system needs permanent maintenance. Self-maintenance is done through various physiological mechanisms tightly linked to each other, including the lymphatic, digestive, renal, lung, nervous, glandular system ... It is not possible to completely separate the physiology of a system from the other adjacent systems because they all work synergistically, being permanently controlled by the central and peripheral nervous system.

The biggest problems with the old hydraulic systems were maintenance and operation because there was always something in the system was blocking somewhere so the whole system stops or works badly.

Even today, it is not easy to maintain a hydraulic system whose circuits have quite large lengths measured in meters.
Then how difficult should it be to maintain the human body's hydraulic system that measures about $100,000 \mathrm{~km}$ in length not for a few hours or days or years, but for a minimum of 100 years, although it may well be as good for 150 years. In fact, just maintaining this functional system for a longer time will prolong the life of the body consistently, this system being very demanding and vital for the human body as well.

By the way, we maintain the blood vessels of our body depend on his health and his life.

The cardiovascular/circulatory system is a device that allows the circulation of blood and lymph in the body to transport nutrients, oxygen, carbon dioxide, etc. It consists of heart and blood vessels, arteries, veins and capillaries that are spread across a dense network throughout the body (Fig. 1).

The heart, weighing 350 grams per adult, has the shape of a cone with the tip pointing down and the base corresponds to the large vessels (caval veins, pulmonary artery, aorta; Tamburrino et al., 2018).

It is a muscular organ whose walls have four layers: the pericardium - the fibrous sac in which the heart, the myocardium (the heart muscle) is housed inside the endocard and on the outside by a serous membrane, the epicardium.

The heart pump has four chambers: the right and left atrium (or right or left ear) with the thin walls - the receiving chambers - and the right and left ventricles with the thicker walls representing the actual pump (Fig. 2). 


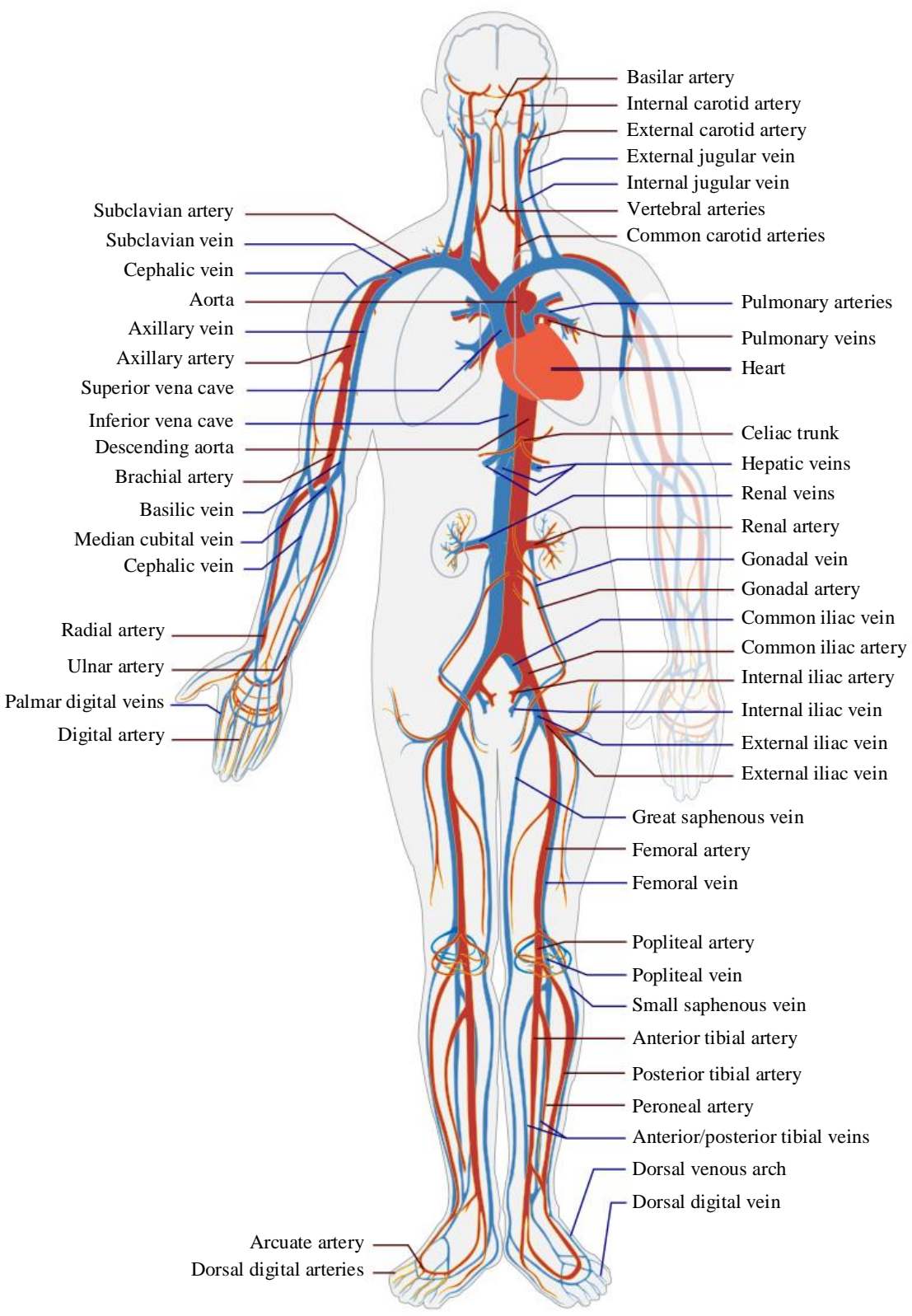

Fig. 1: Simplified diagram of the human Circulatory system

Between the cavities there are communication holes, namely: between the atrium and the left ventricle - the mitral valve, between the atrium and the ventricle as the tricuspid valve; of the left ventricle comes out with the aortic valve aorta and the right ventricle exits the pulmonary artery with its valve. The well functioning of the valves helps the blood filling of the heart during the resting period (diastole) and its propulsion after contraction (systole) in the sea and the small circulation.

The heart is the only muscular organ that rhythmically contracts, without interruption, from embryonic life to death.
Cardiac automatism is provided by a specialized center (the sinus node located in the right atrium), from which the heart stimulus starts and from where it is transmitted further from the atrioventricular node (located in the inter-atrial septum), then from the His beam (from the interventricular septum) and the Purkinje network (from the ventricular walls whose electrical activity gives positive and negative waves on the electrocardiogram (abbreviated ECG)).

The arteries represent the largest blood vessels. They have the role of transporting oxygenated blood from the heart to tissues and organs. 


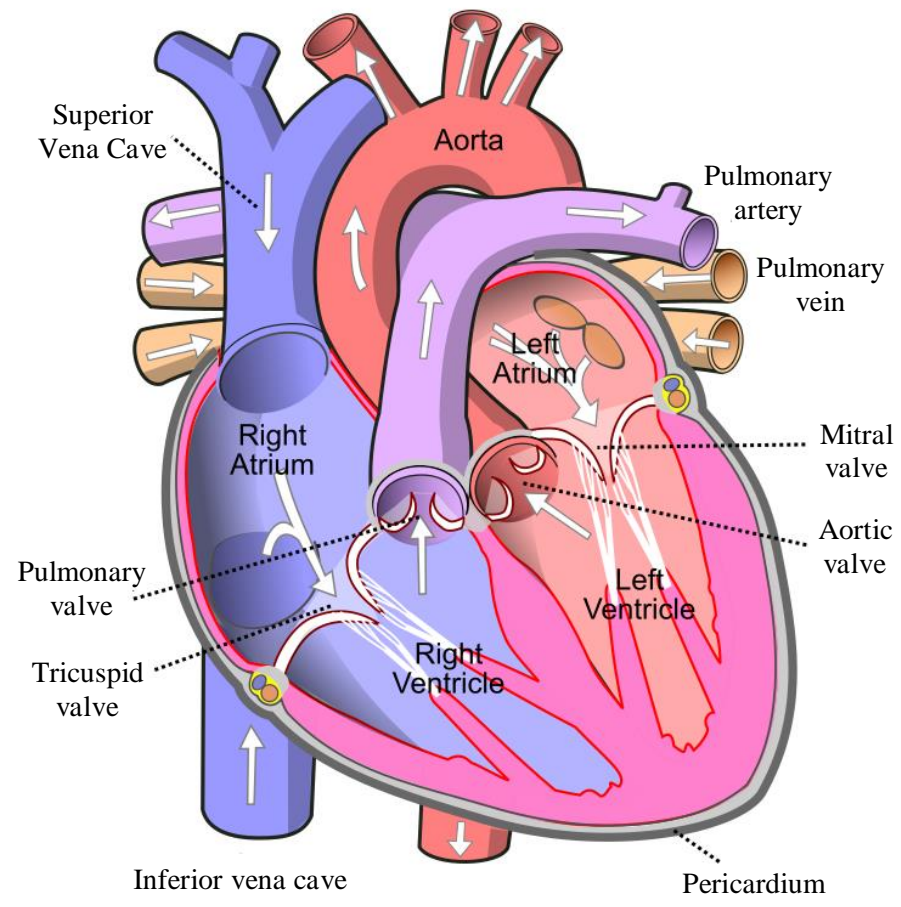

Fig. 2:Diagram of the human heart 1. Superior Vena Cava 2. 4. Mitral Valve 5. Aortic Valve 6. Left Ventricle 7. Right Ventricle 8. Left Atrium 9. Right Atrium 10. Aorta 11. Pulmonary Valve 12. Tricuspid Valve 13. Inferior Vena Cava

The drawings are represented in red. The artery is composed of three layers: the outer tunic, the muscular tunic (middle tunic) and the inner tunic.

The external tunic is made up of connective tissue with collagen and elastin fibers, as well as vegetative nerve fibers and blood vessels providing oxygen for the vascular wall. Medium or medium tunica consists of smooth muscle cells and elastic connective fibers. Internal tunica (also called vascular endothelium) is a simple pavement epithelium found on a basal membrane and an elastic subendothelial layer.

The arteries have the highest pressure due to the constant flow of blood pumped by the heart.

The veins are responsible for transporting the deoxygenated blood from the tissues, organs back to the heart. Unlike the arteries, the boundary between the tunics is not uniform.

The internal tunica below the heart level has dovetailshaped valves, called half-moon, that guide the blood flow; when the blood starts in the right direction, the valves remain open due to cone-shaped positioning. If the blood wants to take it back, they close because of pressure. They are present because there is nothing that pumps the blood back, so he can take it in any direction. Medium tunica is thinner, while the outer one is thicker.
Capillaries are the smallest blood vessels, reaching even a diameter of two or three cells $(15-20 \mu \mathrm{m})$. Because of their size, they can reach anywhere in the body. The oldest capillary network is found on the lung alveoli.

The capillaries result from the ramification of the meta-cartels, continuing with the capillary veins; have $0.5 \mathrm{~mm}$ long. The more metabolic the metabolic activity of the tissue, the more capillaries are present.

Exchanges of gases and other substances are carried out by diffusion and filtration.

Blood pumping is done with the myocardium. When it contracts, the blood passes from the ventricles into the pulmonary arteries, respectively in the aorta, the stage being called systole. After contracting, the diastole follows, where the blood enters the atria in the upper and lower cavity veins and in the pulmonary veins and then in the ventricles.

Circulation is represented by two stages: diastole and systole. They influence blood pressure and heart noises.

The diastole, also called the small circulation, is the passage of blood into the atria in the upper and lower cavity veins (right atrium) and the pulmonary veins (left atrium) and then into the respective ventricles. At this stage, the blood pressure is the lowest. 
Systole, also called large circulation, represents the passage of blood from the ventricles into the pulmonary arteries (right ventricle) and the aorta (left ventricle). This is done by contraction of the heart muscle. At this stage, the blood pressure is highest. Here is also the specific beating of the heart.

Speaking of the circulatory system belonging to the lungs practically we refer to that portion belonging to the cardiovascular system where the blood is depleted of oxygen being pumped very far from the heart, through the pulmonary artery, in the direction of the lungs and then returned, oxygenated, to the heart through the system represented by the vein. pulmonary.

Blood that lacks oxygen from the superior and inferior vena cava penetrates into the right atrium belonging to the heart and then passes through the tricuspid valve (right atrioventricular valve) into the right ventricle, where it will then be pumped through the semilunar pulmonary valve directly into the pulmonary artery to the lungs. This gas exchange that takes place permanently in the lungs and through which $\mathrm{CO} 2$ is released from the blood so that fresh oxygen is absorbed in its place, is the basis of the body's breathing and represents the actual engine of oxygenation of the body and elimination of carbon dioxide from the body, process by which at the end the pulmonary vein returns the blood (now rich in oxygen) to the left atrium.

A separate system known as the bronchial circulation supplies blood to the tissue of the larger airways of the lung (Fig. 3).

The brain benefits from a double source of blood from the front and back arteries. This system can be called the "anterior" and "posterior" circulation, respectively. The anterior circulation originates from the carotid internal arteries having the role of dealing with the front of the brain, while the posterior circulation is represented by the vertebral arteries and nourishes the back of the brain and brain stem.

The front and rear circulation are united (anastomosed) with the Willis Circle.

Renal circulation accounts for about $20 \%$ of all cardiac output and branches directly from the abdominal aorta and then returns to the blood in the ascending vein. Kidney circulation is basically the blood supply to the kidneys and contains many specialized blood vessels.

It must be mentioned from the beginning that the lymphatic system is also part of the circulatory system. It is a network of lymphatic vessels and lymphatic capillaries, lymph nodes and organs and lymphatic tissues and circulating lymph. One of its major functions is the lymphatic transport, drainage and return of the interstitial fluid back to the heart to return to the cardiovascular system, by emptying into the lymphatic channels. The other main function is in the adaptive immune system (Aversa et al., 2017; Armah, 2018; Wilk et al., 2017).

The innervation of the vessels is done through a network of sympathetic nerve fibers, which are also called vasomotor nerves and form nerves called vascular. Nerve fibers are more numerous in the veins than in the arteries. The afferent nerve endings of the arterial level can be classified into baroreceptors and chemoreceptors. Baroreceptors can be identified at the level of the carotid sinus, located immediately below the primary bifurcation of the carotid and the nerve endings come from the XI nerve; Aortic arch.

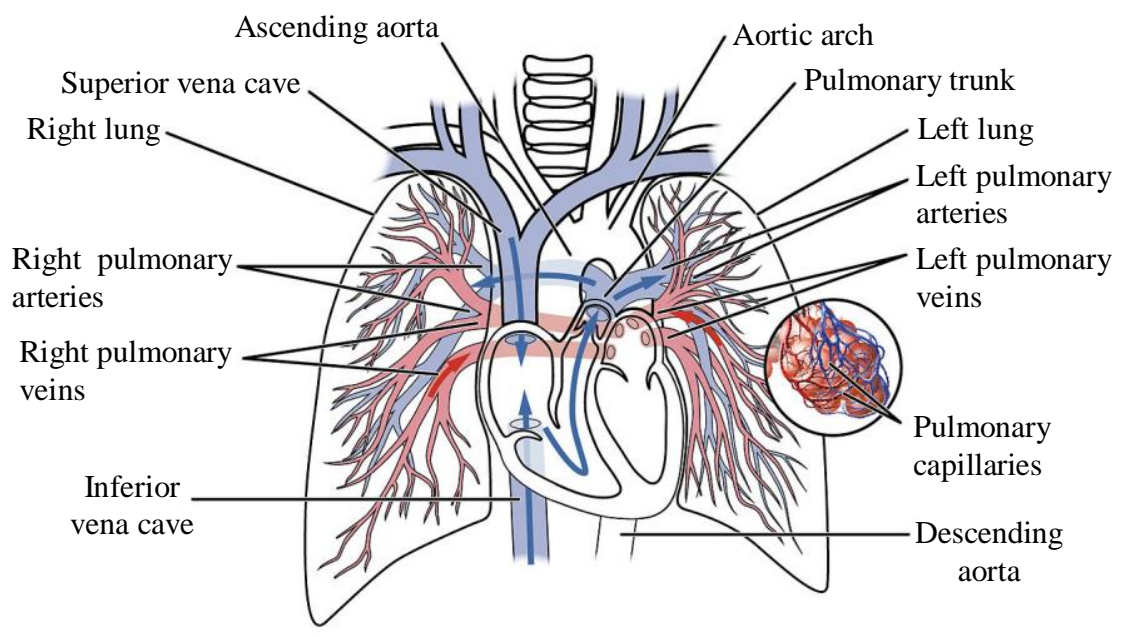

Fig. 3: The pulmonary circulation as it passes from the heart. Showing both the pulmonary and bronchial arteries 
The chemo-receptors can be identified at the level: The Carotid Corpus, located at the level of the carotid bifurcation and consists of two types of glomming cells; The aortic cortex, which is located between the subclavicle and the right carotid, in the right and near the left under the left clavicle.

\section{Materials and Methods}

As already mentioned, this powerful traffic system needs permanent maintenance. Self-maintenance is done through various closely linked physiological mechanisms, including the lymphatic, digestive, renal, pulmonary, nervous, glandular systems ... It is not possible to completely separate the physiology of a system from the other adjacent systems, because all work synergistically, being permanently controlled by the central and peripheral nervous system.

For this reason, the pathophysiology of the renal system will be presented soon.

We are made of water, almost $65 \%$ of everything we stand for because we are human. We are born of water which then gradually loses as we grow older.

This explains the fact that a human embryo is $97 \%$ water, at birth the newborn is made up of $90 \%$ water, the child contains $80 \%$ water, the same child at school age will have $70 \%$ water, while to adult age it will remain only $60-65 \%$ water by weight.

The percentage of water also differs depending on the sex and the percentage of body fat. For women to have a higher percentage of fat (placed in the hands, hips and subcutaneous fat cell tissue) than men, they will have on average 5\% less water than men of the same age. This is because the adipose tissue has the ability to retain a very small amount of water, which explains the reduction of the body's water content.

Water is the environment that holds all biological and chemical reactions in the body, which leads to the production of heat and energy metabolism reactions that need support for life.

In order for these reactions to take place, it is necessary for the substances to be dissolved in water, otherwise they cannot be free of ions and reactions cannot occur.

Water is in the composition of all organs and helps them perform their functions.

Blood contains $90 \%$ water, $75 \%$ muscle, $83 \%$ brain, $86 \%$ lungs, $83 \%$ kidneys, $95 \%$ eyes, $22 \%$ bone. The kidneys need water to filter blood, the digestive tract needs water for digestion, the skin needs water to keep it smooth and healthy and the bones to maintain elasticity and strength (Babaev et al., 2010).

Water circulates through the blood and lymph oxygen and nutrients to the organs. Water helps the elimination of metabolic waste by the kidneys, which is impossible in the absence of a quantity of water that acts as a conductor.

Water participates in the formation and growth of body cells. Water helps maintain the body's constant temperature, causing the body to adjust.

When the body is overheated (in summer or in February) the water eliminates the heat that abounds with perspiration and in winter when the body suffers from cold, the water adapts the body for the purpose of keeping warm blood especially around all vital organs, causing the capillaries to contract to save water losses (Buzea et al., 2015; Petrescu et al., 2015; Petrescu and Petrescu, 2019).

The main energy source of living matter is manufactured in molecules known as ATP (Adenosine Triphosphate). An ATP molecule can convert any solar heat into a form of energy that can be used by plants, humans and animals. An ATP molecule contains these four vital elements: oxygen, hydrogen, nitrogen and phosphorus (thirteen oxygen atoms, eight hydrogen atoms, five nitrogen atoms and three phosphorus atoms).

Of the 28 atoms of an ATP energy molecule, 20 are from the water. Practically important is how the atoms of the four elements are connected in an ATP molecule (Fig. 4).

When the water present at the cellular level is in a small amount, normally neither cells (mitochondria) can produce enough energy from the bulk of the essential raw material water. Then the number of energy molecules (ATP) is reduced. The body becomes weaker (emaciated energy), aging and death.

Through the process of water loss, a reflex of thirst is triggered practically (which means that the dehydration process has practically begun and the body begins to suffer). Sometimes this thirst does not work (to be inhibited by factors such as age, hormonal disorders or a chaotic lifestyle, but that does not mean that the body does not require hydration). In addition, the dehydrated and tired brain refuses to send signals that are suitable for thirst. Therefore, calculated water consumption is required from time to time, whether we are thirsty or not. A serious problem is the loss of water from the cells (loss of cellular water) with age.

The brain is affected. British researchers have found that dehydration causes contraction of the brain size, but returns to normal immediately after consuming a few glasses of water. When we lost water it affected the proper functioning of the brain and nervous system, which leads to the imbalances that we experienced such as nervousness, irritability and anxiety, fatigue, exhaustion and inability to concentrate. Because a dehydrated brain cannot think or process information properly, then intellectual performance is reduced, short-term memory is also affected up to a drop of only $2 \%$ of body water. 


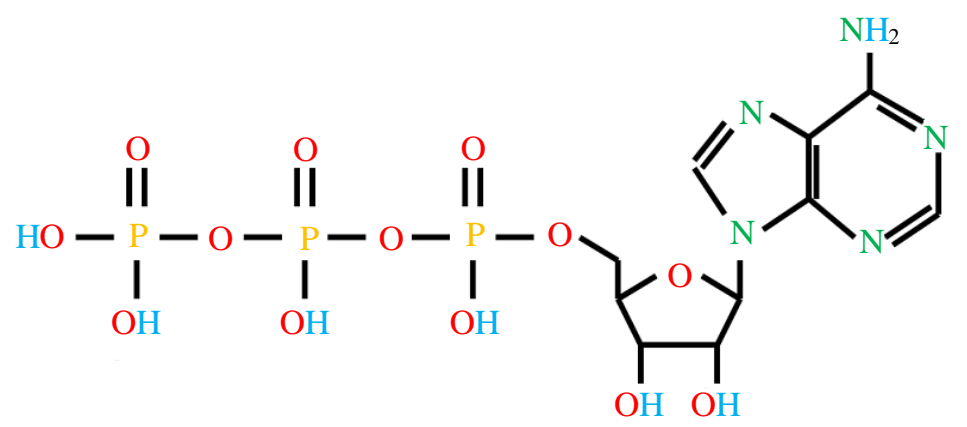

Fig. 4: How the atoms of the four elements are connected on one ATP molecule

When the level of hydration of the body decreases, the lungs slow down their activity, thus limiting the loss of water through respiration, at which time there are large breathing restrictions and the organs no longer function properly and they are also less oxygenated (dizziness and general malaise occur).

When water is low in the body, constipation and decreased urine output appear. Without water, the feces become dry and hard, very difficult to remove (manifested by abdominal pain) and release of toxins into the bloodstream. The urine becomes too concentrated, dark and limited in quantity, which causes the kidneys to not have enough water to eliminate metabolic waste. This concentrated urine promotes the crystallization of calcium, oxalate and uric acid molecules, i.e. kidney stones.

As the water level decreases in the body (dehydration or old age), the skin and mucous membranes dry up. The skin loses elasticity and firmness, gets light wrinkles and can exfoliate. The feeling of "dry mouth" looks red and lips cracked, saliva becomes sticky. The pressure in the eyeballs varies, the eyes cannot produce tears, the sensation of "sand in the eyes" appears.

A headache may occur due to decreased oxygen flow to the brain and poor irrigation. Dehydration may also be the cause of migraines. It has been shown that the best approach to a headache is to drink a glass of water for 10 to $10 \mathrm{~min}$ for one hour.

Fatigue after meals can occur when there is a water shortage in the body. If the digestion process starts on a deficient water background, the blood thickens for the hydration process, it draws water from the vital organs (so they dehydrate) to perform the digestion, which explains why, after eating, we feel tired and starving. If you drink a glass of water before the meal, digestion is without difficulty and we feel energized.

When the body is very dehydrated it can no longer provide water for blood circulation, in which case, the state of shock, hallucinations, fainting state that can culminate with coma and even death can occur.
About $2 / 3$ of the total water for a human body is located in the intracellular compartment (water that is stored as a reservoir inside each human cell).

A third is an extracellular water as follows: $20 \%$ extravascular sector (lymph and interstitial fluid) and 8\% vascular sector (blood water).

Water flows freely and rapidly between all these compartments, in response to changes in solvent concentrations, in order to maintain the balance between the compartments (osmosis).

In an adult of $70 \mathrm{~kg}$, the water is about $40 \mathrm{l}$, of which 251 is intracellular water, extracellular water $15 \mathrm{l}$; In total plasma volume is usually 2.75 to 31 . Intravascular water is at least $85 \%$ in capillary and venous and arterial territories, within $15 \%$. Maintaining the volume of arterial water is highly dependent on blood pressure, the regulation of extracellular fluid volume and the retention of sodium and water.

Sodium is the main extracellular cation and the determinant element for efficient osmosis. The intracellular sodium concentration is on average $15 \mathrm{mmol}$ / 1 and extracellular sodium $140 \mathrm{mmol} / \mathrm{l}$. The average daily sodium intake is $100-200 \mathrm{mmol}$. Sodium absorption occurs in the small intestine and colon. Body water (intro and extracellular) comes on one side of liquids and foods (1-4 1 / day) and on the other side of oxidation of lipids, carbohydrates and proteins (200-500 g daily water).

The water is eliminated nonrenal (loss of skin and airways) and kidneys (through the formation of urine). These water losses play an essential role in the body to eliminate toxins that permanently accumulate in the human body (intro and extracellular). The volume of daily urine intake can be equalized with the elimination of water. Final urine is the result of plasma water filtration (levels of $180 \mathrm{l} /$ day) and resorption (99\% of the filtered water is reabsorbed into the renal tube, of which approximately $66 \%$ is reabsorbed into proximal, iso-osmotic, adjustable, non-transformed; resorption; adjustable; appears in the collecting tube, cortical and medullary). Urine is only $1 \%$ of filtered 
water (1-2 liters/day). Water losses (skin and respiratory) are $650-850 \mathrm{ml} /$ day.

So, about one-third of the water with toxins is eliminated through the skin. In addition, the skin breathes like nostrils, so it is necessary not only to maintain skin cleanliness but also its integrity (without burns or tattoos). Sodium is the main extracellular cation, representing the most important osmotic force that maintains the size of the extracellular fluid volume.

The increase in the total amount of sodium in the extracellular fluid is followed by an increased volume of the fluid compartment and overload. Increase blood pressure. Swelling syndromes (in congestive heart failure, liver cirrhosis, nephrotic syndrome) are medical conditions with an increased amount of sodium in the extracellular compartment (Abdul-Razzak et al., 2012; Ajith et al., 2009; Atasayar et al., 2009).

If the total amount of sodium in the extracellular compartment decreases, the volume decreases and the resulting depletion of the extracellular compartment volume (extracellular dehydration). In this case, the water supply also decreases from the blood, resulting in disorders of the whole body. In case of decreased plasma volume, it can be observed the acceleration of the heart rate, the decrease of blood pressure at bedtime or standing, pale skin and cold extremities, a decrease of urine flow, flattening of neck and forearms, occlusion of blood pressure. If this loss exceeds $30 \%$ of the plasma volume, a hypovolemic shock with cyanosis of the limbs and neurological signs of cerebral hypoperfusion (drowsiness, confusion, agitation) occur.

Maintaining an extracellular volume of salt and water for a long time leads to excessive consumption of intracellular water reserves. It also produces and decreases the volume of interstitial fluid. An interstitial sector is partially responsible for the elasticity and firmness of the skin. Such aging of the skin occurs and of the cells. With the loss of water from cells and energy is lost. Without enough water in the cells, fewer ATP molecules are produced (even if we have enough mitochondria). Cell aging and lack of energy appear.

In contrast, in the case of the growth of the plasma sector, there is an increase in blood pressure.

All processes of a human body are and are finely controlled by various hormones produced by the glands (Abdul-Razzak et al., 2012; Ahmed et al., 2011; Ajith et al., 2009; Alexander and Wang, 2018; Babaev et al., 2010; Buzea et al., 2015; Badziag et al., 1990; Barnard et al., 2003; Barnard and Sternberg, 2007; Beaupre and Hayes, 1985; Bonfield et al., 1981). In this sense, it is important to know the pathophysiology of different human processes. This also happens with the retention or release of sodium and water.

Renin is an enzyme formed and released from the granule cells of the glomus (Ahmed et al., 2011). Renin catalyzes the conversion of angiotensinogen (protein synthesized from the liver) into angiotensin I. Angiotensin I is converted by a conversion enzyme into angiotensin II, which is biologically active (Covic et al., 2007).

Angiotensin II promotes salt retention through direct and indirect effects. It directly stimulates the reabsorption of sodium into the proximal tube (by stimulating the exchange of $\mathrm{Na}+/ \mathrm{H}+$ ). Indirectly, it affects the sodium balance by stimulating the production and release of aldosterone from the glomerular area of the adrenal. Aldosterone induces sodium reabsorption (and $\mathrm{K}+$ secretion) in the distal tube and canal.

Vasopressin or antidiuretic hormone is regulated primarily by the osmolarity of body fluids, but vasopressin also increases in depleted states in volume. This promotes water retention and restoring body fluid volume.

The atrial natriuretic factor is a peptide synthesized by atrial myocytes and released in response to atrial distension. It is efficient to increase the needle by vasodilation of arteriole linked to the increase of DFG (glomerular filtration flow) and loading of the filtered siphon; It has a direct inhibitory action on the absorption of soda in the proximal tube and in the collector of the medullary tube. It has an inhibitory effect on the release of renin, $\mathrm{ADH}$ (antidiuretic hormone) and aldosterone.

Prostaglandins have vasodilating renal action and induce the elimination of sodium and water. They increase the excretion of sodium by increasing the amount of filtered sodium. And all this increases the excretion of water by antagonizing ADH.

The sympathetic nervous system, the reninangiotensin-aldosterone system, the atrial natriuretic peptide and vasopressin are the four main regulators of the systems that adapt their activity in response to changes in body fluid volume.

All processes of a human body are finely controlled by various hormones produced by the glands. In this sense, it is important to know the pathophysiology of different human processes. This also happens with the retention or release of sodium and water.

The sympathetic nervous system, the reninangiotensin-aldosterone system, the atrial natriuretic peptide and vasopressin are the four main regulators of the systems that adapt their activity in response to changes in body fluid volume.

The fact that the decrease in the amount of salt and extracellular water can be kept (much) longer will cause excessive consumption of intracellular water reserves. It also produces and decreases the volume of interstitial fluid. The interstitial sector is partially responsible for the elasticity and firmness of the skin. Such aging of the skin occurs and of the cells. If we have water deficiency at the cellular level automatically the amount of cellular and total energy of the body will decrease. Without enough water in the cells, fewer ATP molecules are produced (even if we have enough mitochondria). Cellular aging and lack of energy appear. 
On the contrary, when an increase in the plasma sector occurs, an immediate increase in blood pressure occurs.

Kidney health depends directly on the health of the whole body. Their disease leads to disease and aging of the body. If we can solve these problems, human life could be extended to 100,150 or 200 years. Some experts say that human aging starts right from birth. It is believed that aging is genetically programmed, but it starts with the moment when the body no longer grows.

Because the most important essential remedy for maintaining the body, but especially for the circulatory and renal system, the heart and brain, together with the central and peripheral nervous system, is vitamin $\mathrm{C}$, that vitamin will be presented now.

If you take into account the statistics established by the WHO regarding the annual deaths caused by coronary heart disease, since the discovery made by Canadian researchers in the 1950 s to date, there have been one billion people who died of cardiovascular disease, which could be cured with vitamin $\mathrm{C}$, if humanity could benefit from the experimental results of the Canadian research team. Deaths from heart disease (caused by chronic scurvy) could be prevented by simple treatment with vitamin C (Willis, 1953, 1957; Willis et al., 1954). What patients are not told is that open heart surgery fails in 40-50\% of cases, because the disease recurs soon after surgery. Resolving the safest and most effective heart disease known, it consists of daily administration of a dose of 6,000 to $10,000 \mathrm{mg}$ of vitamin C (AbdulRazzak et al., 2012; Ahmed et al., 2011; Ajith et al., 2009; Atasayar et al., 2009; Babaev et al., 2010; Buzea et al., 2015). It has long been known that vitamin $\mathrm{C}$ deficiency in the body weakens human arteries by forming atherosclerotic plaques (infiltration of the walls of the aorta and arteries with fat), which blocks blood circulation. Dr. Pauling and his team have found that when arterial plaque is deposited in the arteries, it often appears that a weakened artery is broken and blood clots are formed leading to a heart attack or stroke. Chronic Scurvy responsible for heart disease has been confirmed by cardio-retinometry and has been cured by daily doses of Vitamin C, by Dr. Sidney Bush, of the United Kingdom. Dr. Sidney Bush reported that building pains shrink and then disappear after daily doses of up to $10,000 \mathrm{mg}$ of vitamin C. Based on these observations, he developed a new method of diagnosing coronary heart disease, called cardio-retinometry.

Pericorneal vascularization shows that all people are affected at a certain time of scurvy, the majority suffering from this condition all the time. The chronic subclinical form, not widely known, can be diagnosed using sequential electronic retinal arterial imaging and cured by different amounts of vitamin $\mathrm{C}$ associated with some nutrients.
Free radicals perform many critical functions in our body, checking the passage of blood through the artery to fight infection. Some signal molecules with free radicals that are responsible for starting and stopping genes. Some free radicals, such as nitric oxide and superoxide, are produced in large quantities by our cells immune to viruses and "poisonous" bacteria. However, in less than a second, the free radical can turn against us, can deceive and grow old too quickly. If there is a stroke or heart attack, or just an inflammatory disease, such as arthritis, there are free radicals or they are in production. To understand what free radicals need to be, they are known human cells, in which every day and every second there is a war between free radicals and antioxidants. Like everything in the universe, cells are made up of smaller units called atoms. Each atom contains a nucleus that is surrounded by electrons. Two or more atoms can be linked by dividing electrons that form molecules. The biological oxidation process (the energy formation process) involves the transfer of electrons from one oxygen molecule to another. For these reasons, it can sometimes escape from a single electron. An atom is left without a single electron (an ion) present in the human body, it is called a free radical. Free radicals are constantly forming almost everywhere in the body, in an amazing proportion. If free radicals spread throughout the body are not trapped, they can also attack DNA, the genetic material that controls cell growth and development, can spiral into premature aging or cause much other heavy damage through bodily intoxication (Ha et al., 2010).

Many people consume antioxidants from the network - vitamin C, vitamin E, lipoic acid, coenzyme Q10, glutathione, etc. because they want to look and feel younger (Buzea et al., 2015; Petrescu, 2015). Maintaining antioxidant intake - taking into account free radicals may be one of the most effective ways to slow down the aging process. The antioxidant network (a network of special antioxidants) works together in the body. Only five are considered antioxidants in the network: Vitamin C, Vitamin E, lipoic acid, coenzyme Q10 and glutathione. Vitamins $\mathrm{C}$ and $\mathrm{E}$ are not produced by our body, but must be obtained through food (AbdulRazzak et al., 2012; Ahmed et al., 2011; Ajith et al., 2009; Atasayar et al., 2009; Babaev et al., 2010; Buzea et al., 2015). When an antioxidant encounter a free radical, the radical is automatically connected to the antioxidant molecular structure (El-Gendy, 2009; Enstrom, 2014). The antioxidant becomes a new type of free radical, harmless. This will relieve the cells and the destructive action of the tissues of a free radical out of control. What makes the antioxidant network special is that they can be "recycled" or regenerated after they have broken the power of free radicals, expanding even stronger. For example: when vitamin $\mathrm{C}$ triggers a free 
radical, it becomes a weak free radical in this process. This anti-oxidant can be recycled in the form of Vitamin C. As an anti-oxidant network saves it on the other side, the cycle continues to ensure that the body will maintain the correct antioxidant balance. This particular scenario the antioxidant meets a free radical - it is needed, it becomes a free radical friend - it is recycled for another network of antioxidants - it repeatedly appears in the body, in the blink of an eye. Research has estimated that the number that daily affects the oxidative degradation of DNA in each cell is 10,000 and if that number is multiplied by millions of cells in the body, the scale of these processes in the human body can be understood. Each antioxidant has a unique niche in the cell; for example, in areas with aqueous or blood cells, which consist mainly of water, they will only act on vitamin $\mathrm{C}$ and glutathione. Vitamin $\mathrm{C}$ prevents skin cancer, protecting the DNA from roots without threats In normal quantities, Vitamin $\mathrm{C}$ provides beautiful skin (Buzea et al., 2015; Petrescu, 2015, 2019). Vitamin C is essential for the production of collagen cell glue that holds the body bound and keeps the skin young and supple. It has the essential role of protecting the body against many health problems, especially as we get older. Vitamin $\mathrm{C}$ is considered the center of the antioxidant network, due to the connection between fat-soluble and water-soluble antioxidants. Another essential role of vitamin $\mathrm{C}$ is to recharge vitamin $\mathrm{E}$ which is soluble only in fats, a function fulfilled all the more as it becomes a free radical. Vitamin C (ascorbic acid) is found in the following foods: citrus fruits, green peppers, broccoli, blueberries, strawberries, tomatoes, cabbage (Buzea et al., 2015; Petrescu, 2015).

The minimum daily requirement of Vitamin $\mathrm{C}$ in tissues and cells for a healthy man is $90 \mathrm{mg} /$ day for men, $75 \mathrm{mg} /$ day women, $100 \mathrm{mg} /$ day smokers (Petrescu, 2015). Basically, we need a higher amount of vitamin $C$ daily in the body to determine these amounts to reach all tissues and cells of a healthy body: about 500-1000 $\mathrm{mg} /$ day. When the body is damaged or diseased, the amounts needed to repair the cells are much higher than $5000-10000 \mathrm{mg} /$ day. Whenever it is preferable to obtain our daily requirement of vitamin $\mathrm{C}$ only from food. But, under difficult conditions, when there is a disorder or disease diagnosed, the body that really needs large quantities, must urgently intervene with large quantities of vitamin $\mathrm{C}$ synthesized.

The criminal variety of Canada in Canada, right behind cancer, is heart disease (Hansen et al., 2014). It is the largest cause of hospitalization and the price for the Canadian economy is $\$ 18.5$ billion per year! In fact, which is in everyday reality the first sign of a heart attack that starts or is about to start? The first sign in these situations is death. At least 70 percent of heart attacks occur in people with vascular blockages who do not appear to be detectable by the roentgenogram, most based on the evaluation method used today. On the other hand, over $50 \%$ of people with a heart attack had normal cholesterol and $33 \%$ did not have risk factors for cardiovascular disease.

Natural treatments are made with individualized schemes to prevent heart disease. The first important and necessary step is to determine the health situation. These assessments include blood and urine laboratory tests. Computerized evaluation measures the rigidity of the major artery and aorta. Aortic stiffness increases blood pressure and puts your blood pressure on your heart. Moreover, heart rate variability (which is an important indicator of heart stress) is also measured (Hansen et al., 2014).

Heart disease prevention studies indicate that $93 \%$ of patients can control their blood pressure only with diet by consuming more vegetables and fruits and reducing salt. However, studies show that only $38 \%$ of patients were able to take this regimen. Weight control also prevents heart disease, but as a diet, they are difficult to maintain. In these situations, medical treatment becomes a necessity.

Dr. Linus Pauling, Ph.D., has won 2 Nobel Prizes in drugs and, together with Dr. M. Rath, M.D., has established a cure for heart disease and a way to prevent it (Rath and Pauling, 1990; Rath, 2003). They used high doses of $\mathrm{C}$ food to strengthen the walls of the blood vessels and to stop the injury or rupture of the walls leading to plaque creation and narrowing of the blood vessels. In addition, they used high doses of essential amino acid, AN amino acid, to stop the excessive accumulation of plaque on the vessel walls. Taken, Vitamin C and Lysine are clinically effective. Dr. Robert Cathcart, M.D. has treated over 20,000 patients without developing a case of heart disease.

Dr. U. Ravnskov, M.D., a senior authority on cholesterol theory, says that all cholesterol-lowering drugs are very dangerous to our health and can shorten our lives. All of these drugs are through action by inhibiting the innate ability of the body to produce its own cholesterol. When your own cholesterol production is blocked, significant health complications are created. In general, cholesterol is an important life element for our liver, skin, brain health, heart, etc., which make the body's hormones very important as we grow older. When hormone levels drop, our body responds with increased cholesterol levels to provide the basics for raising our hormone levels (Ravnskov, 2009).

Meanwhile, the world experts in natural medicine claim high cholesterol as a great risk factor, there are other factors contributing to the development of heart disease that is more significant. Thus with respect to heart disease, a more comprehensive approach is needed. Some experts from Harvard have found that inflammation is one of the major causes of heart diseases. Today one 
knows that measurement of blood levels by C-reactive protein (an inflammatory marker), inflammation is a critical indicator in need of investigation.

The need to reduce negative human cholesterol levels started from the need to reduce the risk of cardiac or cerebrovascular accident. Natural medicines have today already a known history of success in preventing and especially the treatment of heart disease, offering some alternative safe and effective treatments to classic pills (which after all are just drugs that do more harm to the body than good, dropping more the good cholesterol needed to the body).

A realistically most common sign of a heart attack is sudden death, unfortunately. Who survived such an attack, however, it was the subject of multiple and difficult tested, treated with a lot of chemical drugs and perhaps, unfortunately, has had to deregulate and one or more surgeries to control the disease. If in some extreme cases surgery and drugs are absolutely necessary today, in most cases they can be replaced by natural methods of treatment (alternative treatments) or when the disease is early (here the prevention can play an important role) or in situations the inflammation did not exceed certain limits.

The alternative (natural) medicine has today more effective and noninvasive treatment options. Therapy Pauling with lysine (an amino acid) and high doses of vitamin $\mathrm{C}$, already has a history officially recognized treatments successful in situations where the disease was early (preventive) and in difficult cases of some patients who already had suffered at least one attack stroke or heart, with one or multiple surgeries and heavy chemical treatments. Chelation therapy with intravenous injections consisting of an essential amino acid that removes heavy metals from the body has a success rate globally certified $87 \%$. Another intravenous therapy, plaques, became a primary treatment for heart disease due to its ability to reduce plaque deposited in the arteries. These alternative treatments are for those with heart failure who can cause fatigue, shortness of breath, angina and numbness in the limbs.

Existing inflammation in the blood has been unanimously identified as a major cause of heart disease and C-reactive protein (which is measured by a simple blood test) can donate valuable information regarding your risk of a heart attack.

An oral or intravenous medication natural can be used to reduce inflammation. Homocysteine and lipoprotein levels can analyze and give useful information on identifying the risk of blood clots. Testing Vital Signs provides a measure of the health of the heart as a score that can identify the health of the heart, specifically the aorta (the major artery). This last test computerized non-invasive blood flow also assesses the state of stress and nervous system learned about the heart.

In 1953, Dr. G. C. Willis, M.D., (a Canadian doctor) first formulated the principle that all cardiovascular diseases are linked to a deficiency of vitamin $\mathrm{C}$ (ascorbic acid) in the body. He found that plaques and inflammation occurring in the blood of patients were due to deficiency of vitamin $\mathrm{C}$ in the body. Based on the idea already known that humans can't synthesize their own vitamin $\mathrm{C}$ as they do generally animals are needed in many situations a filler daily vitamin $\mathrm{C}$ in the body, either naturally (from food) or synthetic (when required doses are higher) (Willis, 1953, 1957; Willis et al., 1954).

In the $1980 \mathrm{~s}$, medical research led to the theory that heart disease starts with a fracture (or stress) produced in the arterial wall. The human body defends itself by producing a single in liver lipoprotein (a) stored as plaque in order to repair the damaged artery wall (These materials they gave a Nobel prize in medicine in 1985). The theory was then supported by German researchers, led by Dr. Beisiegel, which examined postmortem plaques and found only lipoprotein (a) but did not found and cholesterol considered "bad" (LDL cholesterol). Pauling and Rath have understood then that lack of vitamin $\mathrm{C}$ (which can't be manufactured by the liver) force liver to produces and uses instead of vitamin C lipoprotein (a) for the reconstruction of the broken blood vessels.

That was understood that chronic heart disease represents only a consequence of chronic scurvy (lack of vitamin $\mathrm{C}$ prolonged). The liver produces and stores in its place the plaque to repair the tissue absented. But this thread (reserve) has no elasticity and superior properties of fabrics produced normally with the help of vitamin $\mathrm{C}$. On the other hand, needed reconstruction plaque behaves as a concrete, depositing it in large quantities and obstructing the arteries.

Alternative medicine, herbal, has made available to patients (over time) more effective treatment options therapies used varying in function on the specificity and seriousness of the case. One way general treatment was initiated and then generalized in 1989 (after many successful experiments, clinical and then patented in 1994 in the US) by Dr. Linus Pauling, Ph.D. and Dr. Mathias Roth, MD, the treatment being known as "Pauling Therapy" (Rath and Pauling, 1990; Rath, 2003).

Some researchers of the University of California reports that patients taking a daily minimum of 500 milligrams of vitamin $\mathrm{C}$ as a dietary supplement, managed everyone to drop naturally (this way) CReactive Protein (CRP) in the blood by $24 \%$ after about two months of sustained treatment. More recent studies suggest that CRP is a far better predictor of heart disease than cholesterol. C-reactive protein is a real indicator of inflammation in the blood and body and there is today evidence that large chronic inflammation generates both the risk of heart disease or the occurrence of a stroke, but also an increased risk of producing a shape diabetes, Alzheimer's disease or other serious diseases (Dr. Gladys Block, UC Berkeley professor) (Gladys). 
Dr. James Enstrom (University of California) investigated the benefits of the addition of $300 \mathrm{mg}$ vitamin $\mathrm{C}$ daily (food supplement) on 11,000 people in over ten years. He showed that this additional minimal amount administered daily (300mg vitamin C), reduces the risk of heart disease by $50 \%$ in men and $40 \%$ in women (Enstrom, 2014).

G.C. Willis doctor found that all those who consumed $1,500 \mathrm{mg}$ daily dietary supplement of vitamin $\mathrm{C}$, within a year, managed to remove plaque from arteries and those who did not receive the treatment with vitamin $\mathrm{C}$ have suffered an increase of plaque (Willis, 1953, 1957; Willis et al., 1954).

Dr. Sydney Bush has developed a way to test the existence of plaque in the arteries by optometry (photo retina). He could track and assess accurately the existence and plaque thickness deposited in the arteries by this ingenious way of diagnosis. The method was devised in 2002 after being tested on more patients, some of whom were treated daily with vitamin $\mathrm{C}$. The method can accurately predict the amount of vitamin $\mathrm{C}$ present in an organism and additional daily needs.

Vitamin $\mathrm{C}$ (ascorbic acid) contributes to a wide range of benefits. Vitamin $\mathrm{C}$ is known to perform several critical functions within the body involving such as detoxification, tissue-building, strengthen the immune system, pain control and control or kill pathogens. It is known to be helpful for wound and bone healing, healthy skin and eyes, fighting infections, stress management, toxic exposure and repair damaged the tissue of all kinds.

Richard T. Lee, MD, led a team of researchers from Harvard Medical School, in order to test the 880 chemical compounds (all already authorized for use in humans in medicines, supplements, etc.) on their effect on stem cells embryo (in this case collected from mice). All stem cells used were initially treated to emit a certain color green when developed in heart muscle cells and only one chemical issue (from all 880 tested) managed to promote stem cell activity, which is just vitamin $\mathrm{C}$ (Richard).

Vitamin $\mathrm{C}$ has been used in tandem with vitamin $\mathrm{K} 3$ in order to realize an auxiliary treatment against cancer, because vitamin $\mathrm{C}$ is the main antioxidant independent, playing a key role in protecting healthy cells against oxidative stress. When vitamin $\mathrm{C}$ is used in combination with other antioxidants such as glutathione and other drugs such as magnesium, sodium and optionally iodine, it can cause considerable damage to cancer cells, without affecting the healthy cells.

Dr. Sudhir Kurl of the University of Kuopio, Finland conducted a study of more than 2400 overweight patients who had high blood pressure. It was demonstrated that a low level of vitamin $\mathrm{C}$ made the risk of a stroke three times greater (Kunutsor et al., 2016).
If we want to find out more we may read 'Why Animals Don't Get Heart Attacks - But People Do!' by Dr. Matthias Rath (1990; 2003).

Our ancestors have undergone a genetic mutation about 50 million years ago, the mutation that caused the final enzyme in the liver vitamin $C$ synthesis to disappear. For this reason, the human liver has not made it and was so ordinary. The principal missing enzyme is called GLO (gulonolactone oxidase). In animals, it appears and fulfills its function of vitamin $\mathrm{C}$ production in the liver. However, there are some animals such as gorillas, chimpanzees and orangutans which share the same mutation GLO and also can't produce vitamin C. These primates can also have cardiovascular disease, if their food do not donate them enough vitamin C. Except for humans and primates, all other animals have the three enzymes in the liver which can synthesize vitamin $\mathrm{C}$ from glucose (a simple sugar).

Another exception is the guinea pig (guinea pig, a rodent). Guinea pig, for reasons not fully understood yet suffered the same genetic mutation as people and he was deprived of GLO enzyme. However, this is extremely advantageous for us humans as a guinea pig can be used in various experiments needed to study the mechanisms that generate human disease. The gorillas, chimpanzees and orangutans which lack the ability to synthesize vitamin $\mathrm{C}$ also get heart disease.

Steve Hickey and Hilary Roberts have shown in their book and made the statement "Vitamin $\mathrm{C}$ and Tocotrienols can reverse coronary artery disease" (Hickey and Roberts, 2007).

\section{Materials}

Commercially available 2-hydroxyethyl methacrylate (HEMA), obtained from Sigma-Aldrich Chemicals Co., was used as a hydrophilic matrix. (St. Louis, MO, USA). Smoke silicon dioxide (Aerosil 300 Degussa, Germany) with an average diameter of $7 \mathrm{~nm}$ and a specific surface area of $300 \mathrm{~m} 2 \mathrm{~g}-1$ was used as a bioactive filler. Azizobutyronitrile (AIBN) obtained from Fluka (Milan, Italy) was used as the initiator of the radical polymerization reaction. 5, 10, 15, 20 and 25 volumes of HEMA monomers were mixed.

The resin was degassed and transferred into $2.5 \mathrm{~mm}$ thick flat molds and then polymerized in a temperature controlled oven at $60^{\circ} \mathrm{C}$ for $24 \mathrm{~h}$ with a final post-curing temperature of 1 hour at $90^{\circ} \mathrm{C}$ (Aljohani and Desai, 2018; Annunziata et al., 2006; 2008; Apicella et al., 2018a-c; 2015a-b, 2011-2010; 1993; 1982; Armah, 2018; Atasayar et al., 2009; Aversa et al., 2017; 2016a-o; 2009; Comerun, 1986; Čepelak et al., 2013; Chang et al., 2008; Chen et al., 2012; Chow et al., 2010; Cormack and Tilocca, 2012; Covic et al., 2007; Choudhury and Greene, 2018). 


\section{Biomimetic/Biomechanical Approach}

Our biomechanical and biomechanical approach resulted from a physiological, mechanical and physical characterization of the hydrophilic hybrid material in the presence of an aqueous medium simulating physiological fluids (Choudhury, 2018; Davis et al., 1991; El-Gendy et al., 2009; Enstrom, 2014; Filmon et al., 2002; Frost, 1964; 1990; 1994; 2003; Gramanzini et al., 2016; Gorustovich et al., 2010; Greiner et al., 1988; Ha et al., 2010; Hansen et al., 2014).

Physiologically, about $2 / 3$ of total water in a human body is located in the intracellular compartment (water that is kept as a reserve in any human cell). Extracellular water is one-third and distributed: $20 \%$ of the extravascular sector (lymph and interstitial fluid) and 8\% of the vascular sector (water in the blood). Water molecules diffuse freely and quickly between all of these compartments in response to changes in solvent concentrations, while maintaining a balance between compartments (osmosis). Such osmotic and diffuse phenomena have been described as being present in polymeric materials (Holley et al., 1970; Aversa and Apicella, 2016; Hickey and Roberts, 2007; Halpin and Kardos, 1976; Heinemann et al., 2013; Hench and Polak, 2002; Hench and Thompson, 2010; Hench and Wilson, 1993; Hoppe et al., 2011; Huiskes et al., 1987; Hutmacher, 2000; Jarre et al., 2011; Jones and Clare, 2012; Julien et al., 2007; Kabra et al., 1991).

\section{Results}

In a $70 \mathrm{~kg}$ adult, the water is approximately $40 \mathrm{l}$, of which 251 of intracellular water, 151 of extracellular water; in total plasma volume is usually 2.75 to 31 . Intravascular water is at least $85 \%$ in the capillary and venous and arterial region within $15 \%$. Maintaining the volume of arterial water depends largely on blood pressure, extracellular fluid volume regulation and sodium and water retention.

Sodium is the major extracellular cation and the determining factor for obtaining effective osmosis. Intracellular sodium concentration is an average of 15 $\mathrm{mmol} / \mathrm{l}$ and $140 \mathrm{mg} / \mathrm{l}$ extracellular sodium. Daily, the daily average dose is 100-200 mmoles. Sodium absorption occurs in the small intestine and the colon. Body water (intracellular and extracellular) comes on the side of liquids and foods (1-4 1/day) and on the other hand oxidation of lipids, carbohydrates and proteins (200-500 g of daily water).

Water and sorption of dissolved ions can strongly influence the osmotic voltage generated in a polymeric material (Aversa and Apicella, 2016). In our study, two Liquid-like limits based on $\mathrm{NaCl}$ solution were used, including isotonic $(0.15 \mathrm{M})$ and hypotonic $(0.5$
M) solutions to simulate extracellular physiological fluid behavior.

The hydrophilic hybrid material prepared in our study interacts strongly with physiological aqueous solutions. Figure 1 shows the physical phenomena occurring in a 10 $\mathrm{mm}$ long cylinder and $10 \mathrm{~mm}$ diameter of our materials once exposed to an aqueous medium (distilled water).

Initial glass samples sink into distilled water (water activity is unity), swelling due to diffusion and sorption of water molecules, eventually reaching a swollen and elastic state (right bottom right of Fig. 5). The process is characterized by the presence of a clear face that separates the undamaged glass core and without water and an inflated and swollen molecule penetrates into the outer sheath (the lower left hand of Fig. 5).

This specific sorption behavior has been investigated in the past (Holley et al., 1970; Apicella and Hopfenberg, 1982) and refers to the sorption of case II (where there is a change of state) to distinguish it from classical and ordinary sorption from the penetration of causes physical changes).

After immersion in an aqueous medium, this abnormal sorption continues until the sample is completely swollen; because the immersion time is prolonged, in fact, the untreated glass core reduces its thickness (the upper part of Fig. 5).

\section{Mechanical Characterization}

The elastic shear patterns, measured on a dry basis and inflated in different concentrations of $\mathrm{NaCl}$ solutions from the p-HEMA hybrid nanoparticles, were performed using METTLER-TOLEDO mechanical shear mechanic (Zurich, Switzerland). The elastic and viscous components of the shear modulus were measured with a constant frequency in an isothermal state. The dried samples were dried under vacuum at a temperature of $60^{\circ} \mathrm{C}$ for $24 \mathrm{~h}$ prior to testing. In the shear mode, $10 \mathrm{~mm}$ diameter discs and two sample samples cut from the polymer plate were placed between three steel plates forming a symmetrical sandwich. Isothermal scans were performed at $37^{\circ} \mathrm{C}$ in dry nitrogen. The deformation control was set at $10 \mu \mathrm{m}$ and a force limit of $0.9 \mathrm{~N}$ was applied at an oscillating frequency of $10 \mathrm{~Hz}$ (Karageorgiou and Kaplan, 2005; Kim et al., 2004; Krueger et al., 2008; 2006; Kunutsor et al., 2016; Lai and Barnard, 2011a-b; Mano et al., 2004; Marquetti and Desai, 2018; Marrelli et al., 2015; Martin et al., 1998; Mohan et al., 2010; Montheard et al., 1992).

The same procedure was applied to the swollen polymer (without drying and $0.09 \mathrm{~N}$ force limitation); Hypotonic 5-25\% vol. of the analyzer in a dry nitrogen atmosphere at $10 \mathrm{~Hz}$ and $37^{\circ} \mathrm{C}$; The shear modulus of the dried and swollen samples (for samples of different compositions) are graphically represented in Fig. 6 on a logarithmic scale. 


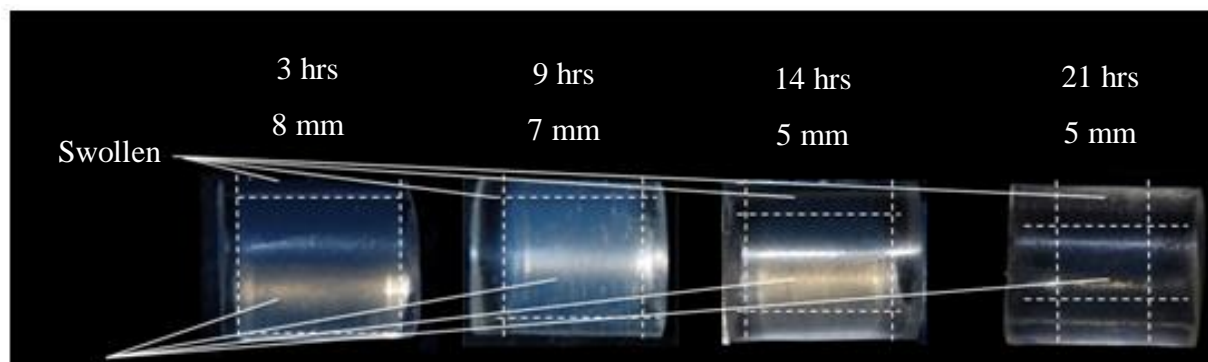

Solvent unpenetrated glassy core

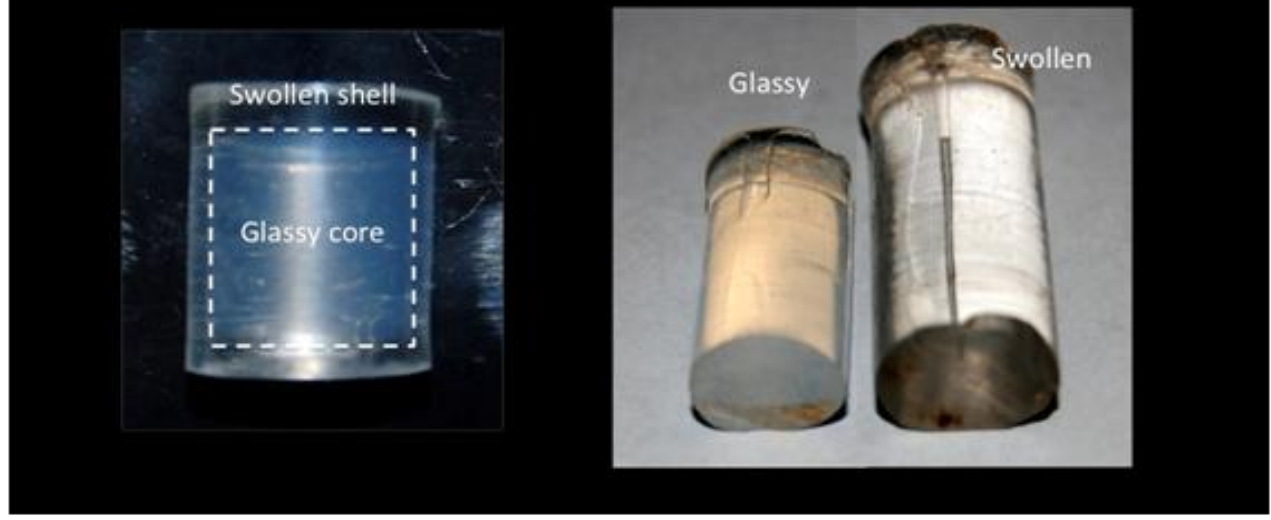

Fig. 5: Swelling behavior of our hybrid hydrophilic nanocomposite in water

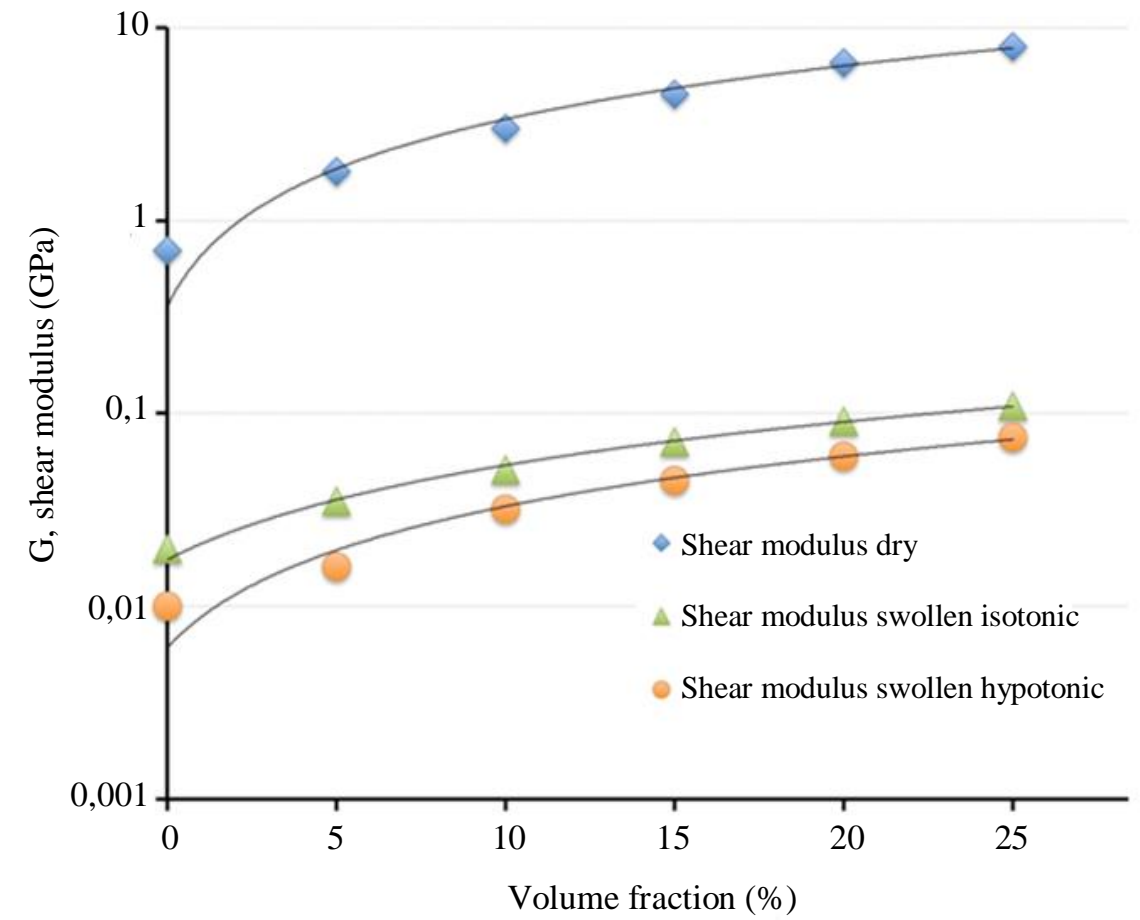

Fig. 6: Shear moduli of dry and swollen (rubbery) of our hybrid hydrophilic nanocomposites equilibrated in hypotonic and isotonic aqueous solutions

A significant plasticization effect was induced by balancing in saline physiological solutions. The stamping modules of the glass and glass samples range from 0.8 to $9 \mathrm{GPa}$, varying between 0.01 and $0.1 \mathrm{GPa}$ for 
sweetened and swollen rubber samples. The less concentrated hypotonic aqueous solution induced a higher level of plasticization (lower modes).

Moreover, the samples exhibited predominantly elastic behavior (the viscous component was negligible for all compositions). Aversa et al. (2016a) demonstrated that the measured shear modulus of the various compositions of the PHEMA-Nanosilica composition did not follow the classical Halpin and Kardos (1976) equation for particulate composites. A linear dependence of shear modulus values on a progressive load on sodium silicate has been described. This unexpected behavior confirmed the hybrid nature of pHEMA silica compounds.

The mechanical shear modules of the dried and swollen samples reported in Fig. 6 were then interpolated by linear fitting (the entire line in Fig. 6).

To obtain the mechanical properties required for bone replacement, the nanofiller/p-HEMA compositions for the appropriate hybrid nanocomposites are:

- When glassy and dry, it must be comparable during bone stiffness $(\mathrm{G}=2-4 \mathrm{GPa})$

- Once swollen, it must be comparable during the osteointegration step with cartilage and ligament elasticity of $10-40 \mathrm{MPa}$

Shear modulators comparable to those of cortical bone were measured dry for voluminous nano silicone fractions ranging from 5 to $10 \%$. A $5 \%$ volume fraction was then chosen to characterize sample composition and sorption behavior.

The shear modulus of 16 and $35 \mathrm{MPa}$ was experimentally found for the hybrid compound (5\% by volume) swollen in isotonic and hypotonic solutions, respectively. This value becomes comparable to that of the periodontal ligament in the same condition as articular cartilage (Toyrasa et al., 2001; Comerun, 1986; Morales-Hernandez et al., 2012; Mouriño et al., 2012; Ozawa et al., 2007; Osswald et al., 2006; Parfitt, 1983; 1994; Peluso et al., 1997; Perillo et al., 2010).

\section{Sorption and Swelling Tests}

Sampling samples of $2.0 \mathrm{~mm}$ thickness and $20 \times 20$ $\mathrm{mm}$ of $5 \%$ nano silicon hybrid prepared according to conditions in the kinetic characterization section and abnormal equilibrium in aqueous physiological isotopes and hypotonic saline solutions $(0.5$ and $0.1 \mathrm{M} \mathrm{NaCl})$. These two solutions were chosen to simulate two possible different conditions of physiological extracellular fluids that can be encountered for the elderly, sex or physical differences.

As discussed previously, in fact, the percentage of water in the extracellular fluid differs for the percentage of sex and body fat. Women who have a higher percentage of fat than men have an average of $5 \%$ less water than men of the same age.

The aqueous solution absorbed in the initially dried samples was determined at equilibrium by gravimetric measurements in a Mettler Toledo analytical balance of $0.1 \mathrm{mg}$ precision and reported in Fig. 7 .

Similarly, the advancement and penetration of the inflated fronts of the aqueous medium into the abnormal sorption of the boundary II (Nicolais et al., 1984; Apicella and Hopfenberg, 1982) observed in our hydrophilic samples were monitored over time by measurement, Leitz Microscope, 8) and the total thickness that increases on the $\mathrm{Z}$-axis and the variations in the lengths along the two orthogonal axes (X and $\mathrm{Y}$ ) in the plane of the plate sample (Fig. 10).

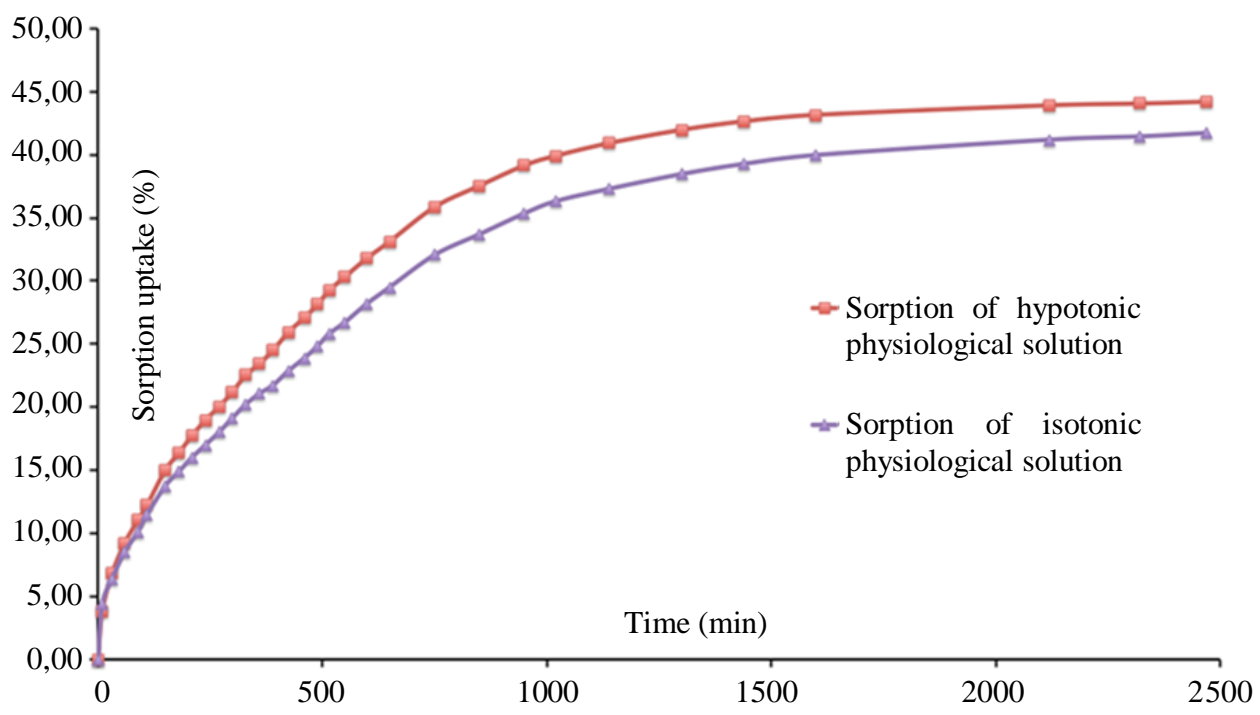

Fig. 7: Swelling and sorption kinetic in a $5 \%$ by volume hybrid nanocomposite in physiological $0.05 \mathrm{M}$ (hypotonic) and $0.15 \mathrm{M}$ (isotonic) $\mathrm{NaCl}$ solutions 


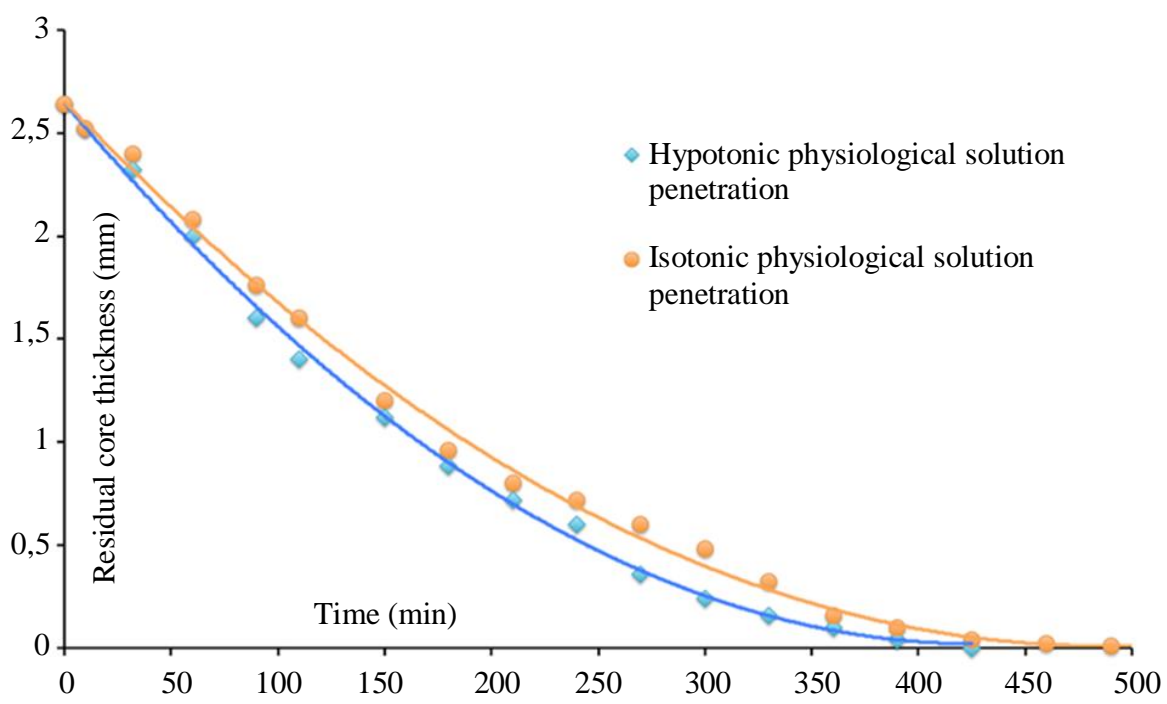

Fig. 8: Residual glassy core thickness reduction kinetic in a $5 \%$ by volume hybrid nanocomposite swelled in physiological $0.05 \mathrm{M}$ (blue circle, hypotonic) and $0.15 \mathrm{M}$ (orange circle, isotonic) $\mathrm{NaCl}$ solutions

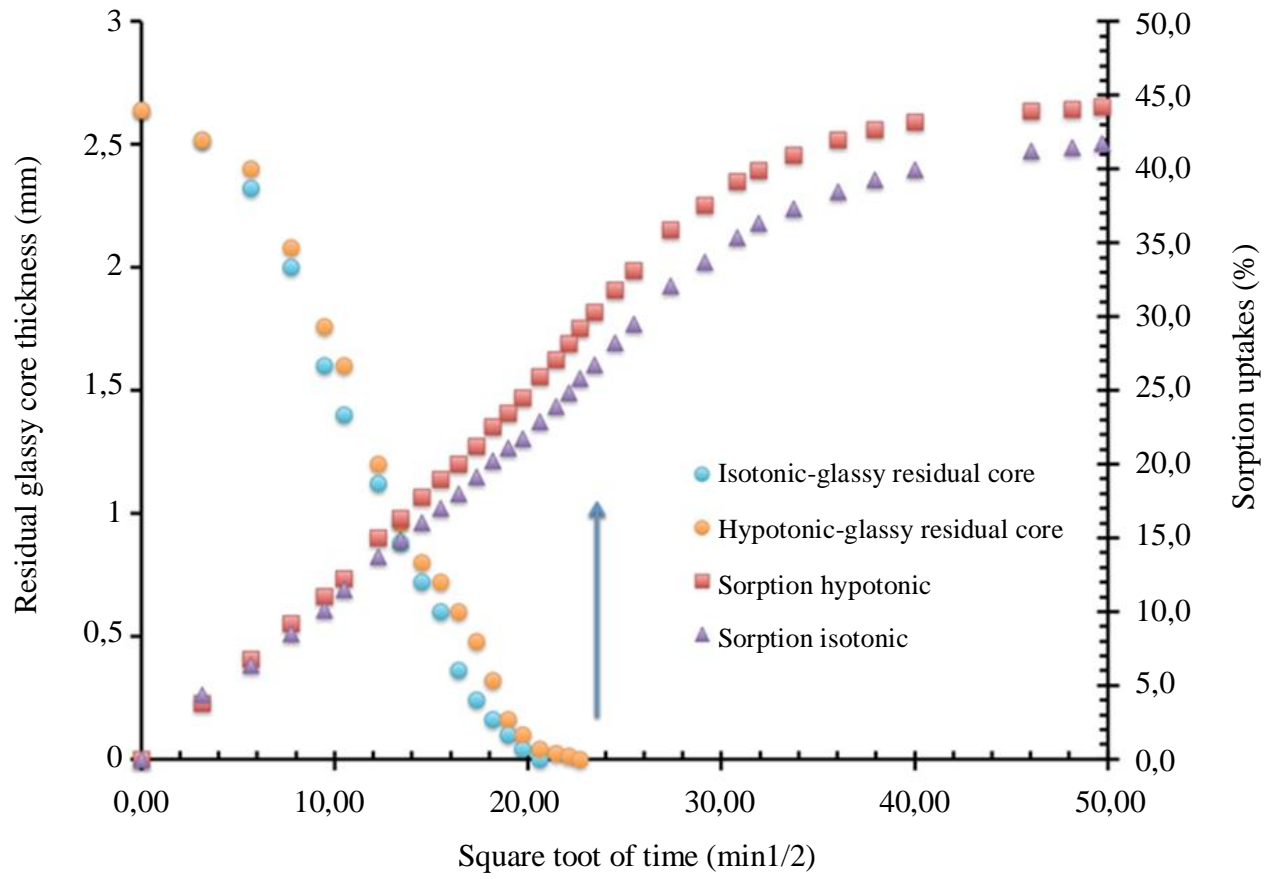

Fig. 9: Swelling and sorption kinetic as a function of the square root of the time in the 5\% by volume hybrid nanocomposite in physiological $0.05 \mathrm{M}$ (hypotonic) and $0.15 \mathrm{M}$ (isotonic) $\mathrm{NaCl}$ solution

All sorption and equilibrium swelling experiments were performed at $37^{\circ} \mathrm{C}$ (thermostatic water bath) to a constant weight (100 h).

The sorption behavior in an isotonic and hypotonic physiological solution of our hybrid glass materials with a volume fraction of $5 \%$ has been investigated for both weight absorption and swelling kinetics. Inflation modeling and kinetics were represented by time (Fig. 7, 8 and 10) and the square root of time (Fig. 9).

Figure 7 shows the data for obtaining the absorption weight of the primer according to the immersion time in the two hypotonic and isotonic physiological solutions. 


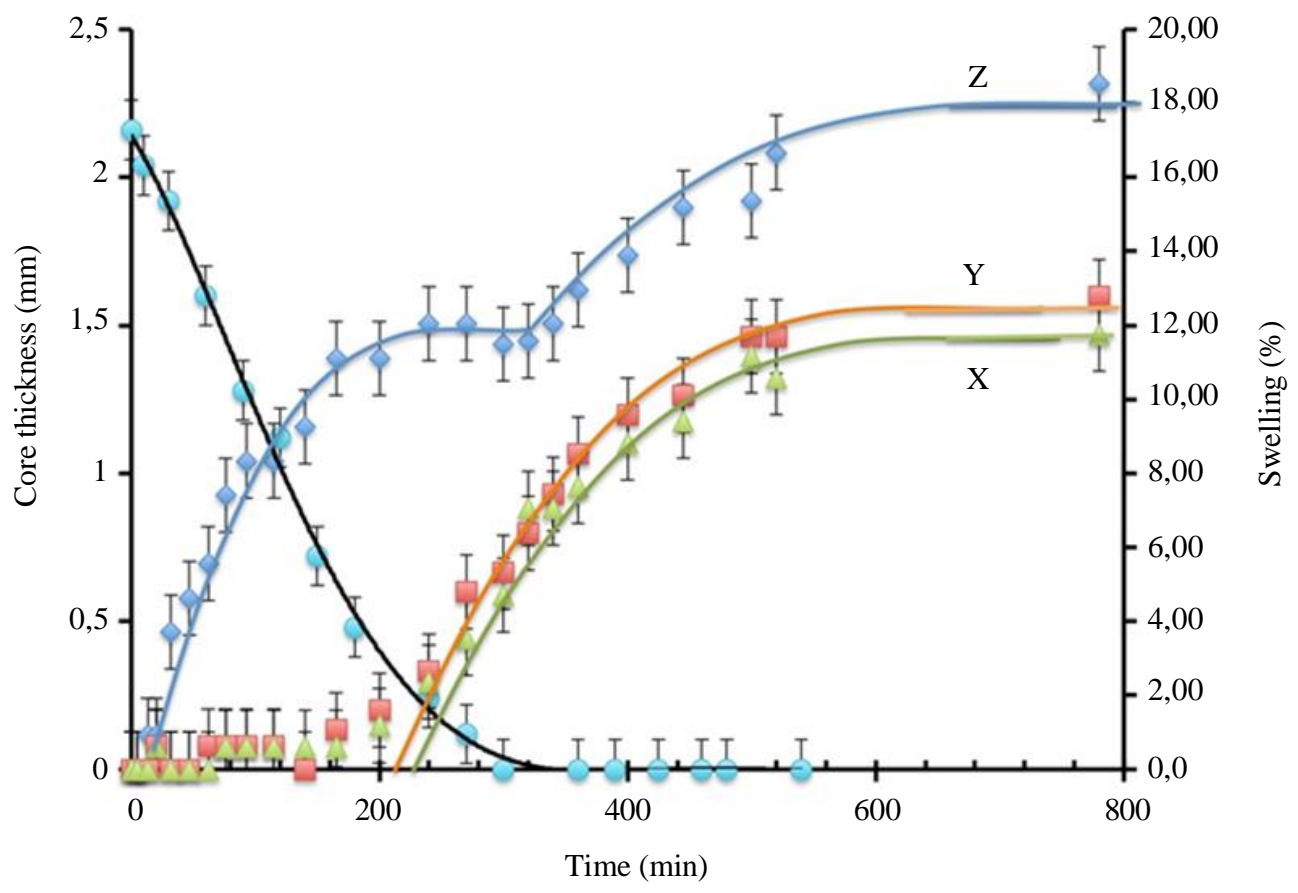

Fig. 10: Percent swelling (right axis) and glassy core thickness reduction (left axis) for the 5\% by volume fumed silica hybrid nanocomposite in physiological $0.15 \mathrm{M}$ (isotonic) $\mathrm{NaCl}$ solution

The 5\% hybrid nanocomposite swells dramatically in isotonic aqueous solution (Fig. 7), elevating 42-45\% of its dry weight and reducing its shear modulus to 15-25 MPa (as measured in the DMA assays of Fig. 6). Such a phenomenon is associated with water-induced polymer plasticization, which reduces the transition temperature of the polymer glass below the test temperature (Petrescu and Calautit, 2016a-b; Petrescu et al., 2015; 2016a-e; 2017; 2018; Petrescu, 2019; Prashantha et al., 2001).

After exposure to the aqueous solution, $2 \mathrm{~mm}$ thick coated PHEMA glass plates begin to swell with a clear face dividing the outer rubber portion and the untreated glass core. The progressive thickness of the core glass decreases as the swollen front advances through the sample. A measure of the swollen kinetics, which was reported in Figs. 8 and 9, depending on the square root of the time, is given by the rate of reduction of the thickness of the glass core. The inflated face initially observed progressed at a constant rate, in accordance with the relaxed relaxed relaxed relaxation mechanism, indicated as "case II sorption" (Nicolais et al., 1984).

The initial linear inflation rate (Fig. 4) is slower for the isotonic solution, about $0.10 \mathrm{~mm} / \mathrm{h}$ and faster, about $0.13 \mathrm{~mm} / \mathrm{h}$, for the hypotonic solution. As the swelling continues, however, diffuse resistance to the flow of water molecules develops into the swollen outer layer, reducing the rate of inflation of the remaining glass core (Apicella and Hopfenberg, 1982).
Once the glass core has disappeared (indicated by an arrow in Fig. 9), i.e. after 425 and 500 min (see right side of Fig. 9) for the hypotonic and isotonic solution, the weight absorption of the samples is approximately $25 \%$ Fig. 9) for less concentrated and concentrated isotonic solutions (Reilly and Burstein, 1974; 1975; Schiraldi et al., 2004; Schrand et al., 2009a-b; Schwartz-Dabney and Dechow, 2003; Shenderova et al., 2011; Sorrentino et al., 2009; 2007; Tamburrino et al., 2018; Taylor et al., 2007; Töyräsa et al., 2001; Viecelli et al., 2001; Wilk et al., 2017).

This refers to achieving complete inflation equilibrium once the glass core does not more constrain deformations along the $\mathrm{X}$ and $\mathrm{Y}$ axes of the sampling plate (Fig. 10).

This particular behavior can be deduced from the swelling data reported in Figure 10 where the swelling ratio in the $\mathrm{X}, \mathrm{Y}$ and $\mathrm{Z}$ directions (right side of Fig. 10) is reported and compared to the reduction in core thickness (Fig. 10).

Along the Z-axis (depending on the thickness), the swing curve reaches the first $12 \%$ plate in correspondence with the base glass exhausts and then repeats to increase.

On $\mathrm{X}$ and $\mathrm{Y}$ axes, swelling is initially inhibited by the presence of the rigid glass core. Once it disappears, however, the swelling starts and reaches the final value of about $12 \%$. Swelling along with the thickness, inversely, continues after inflated fronts meet and reach a final value of $18 \%$. 
This evidence indicates that a plastic deformation has taken place in the $\mathrm{Z}$ direction.

In 1998 three researchers won the Nobel prize in medicine for discovering the major importance of nitric oxide and it is now 20 years since it is known that it is more important than oxygen, for example, for the proper functioning of our body. Author of over 300 papers published in some valuable medical journals, a member of the European Academy of Sciences, Professor Ihor Huk told us about the importance of this molecule and what we can do to have it in the body.

Prof. Ihor Huk: "I often ask students what is most important to our lives - oxygen or nitric oxide? Of course, both are vital, but most often the answer is oxygen because $99 \%$ think we can't survive without oxygen. In fact, this is not the truth - the heart can function longer without oxygen than without nitric oxide. If it were somehow extracted from the heart, the heart would stop immediately. Also, memory works with the help of nitric oxide; the immune system fights bacteria, viruses, cancer cells with the same substance, nitric oxide. Basically, the proper functioning of the brain and heart depends essentially on the existence of nitric oxide in sufficient quantities in the body and distributed where it is essential.

Nitric oxide is also responsible for blood pressure, it is the most important vasodilator. Now understand why I say that nitric oxide is more important than oxygen. Oxygen is much easier to obtain - we just have to breathe, but nitric oxide is obtained through nutrition. In 1998 three researchers won the Nobel Prize in medicine for discovering the major importance of nitric oxide and it is already 20 years since it is known that it is much more important than oxygen, for example, for the proper functioning of our body.

The cells are very clever and extract the substances they need - in this case, nitric oxide, but it is important to feed them properly. Because we cannot assimilate nitric oxide from food, we need foods containing arginine, a substance that the body synthesizes in nitrogen and then nitric oxide. What do we feed on? Pumpkins! - have the highest concentrations of arginine, walnuts as well (100-150 grams daily, ideally). Thus, a sufficient amount of arginine will be obtained for the proper functioning of the body. Memory, blood circulation will be markedly improved.

But because we live in times when we travel often and have a lot to do, I recommend food supplements. In order for the body to function properly (and never get sick), humans need arginine (which is subsequently converted into the body into nitric oxide), but also calcium, vitamin D3 (today it is considered a hormone) and vitamin $\mathrm{K} 2$. I checked this on many of my patients and, believe me, it works!

I consume a lot of vitamin D daily (between 15,000 and 20,000 units a day), much more than it would be recommended initially (2000 IU) and I have absolutely no problem. What the doctors usually recommend is related to the old knowledge from the seventeenth century and no longer applies today. There is no risk of an overdose of vitamin D, it is impossible. Only 2000 units a day are too few to support the optimal functioning of the body. If the level is low, we have hypertension. Vitamin D is essential for the absorption of nitric oxide! For nothing, we provide the necessary nitric oxide to the body if we do not assimilate it, or its absorption is via vitamin D3" (I. Huk, Nitric oxide).

Originally known as a relaxing factor derived from endothelium, nitric oxide (NO) has been extensively studied over time, its importance in the body being fully recognized in 1998 when the Nobel Prize for Medicine was awarded to a team of researchers for studies on biological effects. of this molecule. Nitric oxide has been identified as a messenger in the central nervous system (CNS), being known as an unstable intracellular factor, which mediates increased levels of cyclic guanosine-3-5monophosphate (GMPc) (Derbyshire and Marletta, 2009; Shinde et al., 2000).

The discovery of the signal-molecule function in the brain of NO has opened a new dimension to the concept of neuronal communication, surpassing the classical image of chemical neurotransmission, where information is transmitted through synapses in one direction (Hill et al., 2010). An important property of NO, which differentiates it from other CNS mediators, is diffusibility. This is increased in both the aqueous and lipid environments, allowing for three-dimensional signal scattering, which does not take into account the presence of membranes (Lee et al., 2009).

Despite its structural simplicity, NO has a complex chemistry, endowing the free radical with wide and varied biological actions. This free radical is an ephemeral species with a half-life of only five seconds. $\mathrm{NO}$, as a radical with increased reactivity, diffusibility and instability, plays an important role in regulating a wide range of physiological processes, including cell immunity, angiogenesis, cardiac function, neurotransmission and platelet aggregation (Webb et al., 2008; Massion et al., 2005).

Therapeutic use is limited by its short shelf life, instability during storage and its toxic potential. Taking all this into consideration, drugs were obtained in the form of NO molecular carriers (also called NO donors), made to stabilize this radical, until it is needed for its release (Eroy-Reveles and Mascharak, 2009; Bryan et al., 2009).

In the last ten years, there have been numerous attempts to obtain NO donors, among which promising ones seem to be in particular diazene-diolate derivatives, S-nitroso-thiols, hybrid donors of $\mathrm{NO}$ and NOgenerating compounds (Miller and Megson, 2007). Despite the obvious potential of NO, no significant progress has been made in obtaining NO donors, given the scientific enthusiasm generated by identifying this 
molecule as an important biological messenger (EroyReveles and Mascharak, 2009).

\section{Discussion}

Water plays a critical role in the physiological balance of the human body. Water can be removed from the body by the loss of skin, breathing and kidneys (through urine formation). These water losses play an essential role in eliminating toxins that accumulate permanently in the human body (intracellular and extracellular). An equivalent daily intake volume may be equivalent to eliminating urine. The final urine is the result of plasma water filtration (180 1/day) and reabsorption ( $99 \%$ of the filtered water is reabsorbed in the renal tube, of which approximately $66 \%$ is reabsorbed into the convertible isosmotic convertible tube into the medullary tube). Urine represents only $1 \%$ of the filtered water (1-2 liters/day). Water loss (skin and breath) is 650$850 \mathrm{ml} /$ day. So about, a third of the toxin water is removed through the skin. In addition, the skin breathes like nostrils, so it is necessary not only to keep the skin clean but also its integrity. Sodium is the major extracellular cation, representing the most important osmotic pressure that maintains the extracellular fluid volume.

Increase in a total amount of sodium in the extracellular fluid is followed by an increased volume of the extracellular fluid compartment and extracellular fluid overload. Increase blood pressure. Inflammatory syndromes (in congestive heart failure, hepatic cirrhosis, nephrotic syndrome) are medical conditions with increased amounts of sodium in the extracellular compartment.

If the total amount of sodium in the extracellular compartment decreases, the volume decreases, resulting in a decrease in the extracellular compartment volume (extracellular dehydration). In this case, the intake of water also decreases from the blood, leading to disorders of the whole body. In case of decreased plasma volume in this sector, accelerated heart rate decreased blood pressure in the skin or feet, palpitations and cold extremities, decreased urine, flattened forearms of the neck and forearm, blood pressure occlusion. In the case of loss of more than $30 \%$ of the plasma volume, there are hypovolemic shocks with lymph cyanosis and neurological signs of cerebral pituitary (somnolence, confusion, agitation).

Maintaining the decrease in extracellular salt volume and water can lead to excessive consumption of intracellular water reserves. It also produces and reduces interstitial fluid volume. The interstitial sector is partly responsible for the elasticity and firmness of the skin. Such aging of the skin also occurs in cells. With water loss of cells and energy is lost. Without enough water in the cells, fewer ATP molecules are produced (even if we have enough mitochondria). Aging cells also leads to a lack of energy. Instead, in the case of plasma growth, there is an increase in blood pressure (Rath and Pauling, 1990; Rath, 2003; Ravnskov, 2009; Willis, 1953, 1957; Willis et al., 1954; Wolff, 1892; Xiao et al., 2014; Yuan et al., 2010; Zhang et al., 2011).

Renin is an enzyme formed and liberated by granular cells. Renin catalyzes the conversion of angiotensinogen (synthetic hepatic protein) to angiotensin I. Angiotensin I is transformed by an enzyme that converts to angiotensin II, which is biologically active.

All the processes of a human body are finely controlled by the various hormones produced by the glands. In this sense, it is also important to know the pathophysiology of different human processes. This also happens with the retention or release of sodium and water.

Such changes in the level of sodium ions can cause changes in the physical and mechanical properties of biomaterials when used for structural systems or hydrophilic scaffolds.

Our hybrid materials have been designed to act as a biocompatible skeletal implant and for a bioactive dental implant to promote bone growth in the OB adaptive implant. In order to achieve this result, both a biocompatible material and a biomechanical material suitable for scaffolding must be designed.

Vitamin $\mathrm{C}$ has been used in tandem with vitamin $\mathrm{K} 3$ in order to realize an auxiliary treatment against cancer, because vitamin $\mathrm{C}$ is the main antioxidant independent, playing a key role in protecting healthy cells against oxidative stress. When vitamin $\mathrm{C}$ is used in combination with other antioxidants such as glutathione and other drugs such as magnesium, sodium and optionally iodine, it can cause considerable damage to cancer cells, without affecting the healthy cells.

Dr. Sudhir Kurl of the University of Kuopio, Finland conducted a study of more than 2400 overweight patients who had high blood pressure. It was demonstrated that a low level of vitamin $\mathrm{C}$ made the risk of a stroke three times greater (Kunutsor et al., 2016).

If we want to find out more we may read 'Why Animals Don't Get Heart Attacks - But People Do!' by Dr. Rath and Pauling (1990; Rath, 2003).

Our ancestors have undergone a genetic mutation about 50 million years ago, the mutation that caused the final enzyme in the liver vitamin $C$ synthesis to disappear. For this reason, the human liver has not made it and was so ordinary. The principal missing enzyme is called GLO (gulonolactone oxidase). In animals, it appears and fulfills its function of vitamin $\mathrm{C}$ production in the liver. However, there are some animals such as gorillas, chimpanzees and orangutans which share the same mutation GLO and also can't produce vitamin C. These primates can also have cardiovascular disease, if their food do not donate them enough vitamin C. Except 
for humans and primates, all other animals have the three enzymes in the liver which can synthesize vitamin $\mathrm{C}$ from glucose (a simple sugar).

Another exception is the guinea pig (guinea pig, a rodent). Guinea pig, for reasons not fully understood yet suffered the same genetic mutation as people and he was deprived of GLO enzyme. However, this is extremely advantageous for us humans as a guinea pig can be used in various experiments needed to study the mechanisms that generate human disease. The gorillas, chimpanzees and orangutans which lack the ability to synthesize vitamin $\mathrm{C}$ also get heart disease.

Steve Hickey and Hilary Roberts have shown in their book and made the statement "Vitamin $\mathrm{C}$ and Tocotrienols can reverse coronary artery disease" (Hickey and Roberts, 2007).

Prof. Ihor Huk: "I often ask students what is most important to our lives - oxygen or nitric oxide? Of course, both are vital, but most often the answer is oxygen because $99 \%$ think we can't survive without oxygen. In fact, this is not the truth - the heart can function longer without oxygen than without nitric oxide. If it were somehow extracted from the heart, the heart would stop immediately. Also, memory works with the help of nitric oxide; the immune system fights bacteria, viruses, cancer cells with the same substance, nitric oxide. Basically, the proper functioning of the brain and heart depends essentially on the existence of nitric oxide in sufficient quantities in the body and distributed where it is essential.

Nitric oxide is also responsible for blood pressure, it is the most important vasodilator. Now understand why I say that nitric oxide is more important than oxygen. Oxygen is much easier to obtain - we just have to breathe, but nitric oxide is obtained through nutrition. In 1998 three researchers won the Nobel Prize in medicine for discovering the major importance of nitric oxide and it is already 20 years since it is known that it is much more important than oxygen, for example, for the proper functioning of our body.

The cells are very clever and extract the substances they need - in this case, nitric oxide, but it is important to feed them properly. Because we cannot assimilate nitric oxide from food, we need foods containing arginine, a substance that the body synthesizes in nitrogen and then nitric oxide. What do we feed on? Pumpkins! - have the highest concentrations of arginine, walnuts as well (100-150 grams daily, ideally). Thus, a sufficient amount of arginine will be obtained for the proper functioning of the body. Memory, blood circulation will be markedly improved.

But because we live in times when we travel often and have a lot to do, I recommend food supplements. In order for the body to function properly (and never get sick), humans need arginine (which is subsequently converted into the body into nitric oxide), but also calcium, vitamin D3 (today it is considered a hormone) and vitamin $\mathrm{K} 2$. I checked this on many of my patients and, believe me, it works!

I consume a lot of vitamin D daily (between 15,000 and 20,000 units a day), much more than it would be recommended initially (2000 IU) and I have absolutely no problem. What the doctors usually recommend is related to the old knowledge from the seventeenth century and no longer applies today. There is no risk of an overdose of vitamin D, it is impossible. Only 2000 units a day are too few to support the optimal functioning of the body. If the level is low, we have hypertension. Vitamin D is essential for the absorption of nitric oxide! For nothing, we provide the necessary nitric oxide to the body if we do not assimilate it, or its absorption is via vitamin D3.

\section{Conclusion}

All processes of a human organism are finely controlled by various hormones produced by the glands, which can alter both the extracellular water content and the sodium ion concentrations:

Angiotensin II promotes salt retention through direct and indirect effects. It directly stimulates sodium reabsorption in the proximal tube (by stimulating $\mathrm{Na}+$ / $\mathrm{H}+$ exchange). Indirectly, it affects the balance of sodium by stimulating the production and release of aldosterone in the glomerular area of the adrenal glands. Aldosterone induces sodium reabsorption (and $\mathrm{K}+$ secretion) in the distal tube and distal canal.

Vasopressin or the antidiuretic hormone is mainly regulated by the osmolarity of body fluids, but vasopressin also increases in the volume depletion state. This promotes water retention and restoration of body fluid volume.

The atrial natriuretic factor is a peptide synthesized by atrial myocytes and released in response to atrial dysfunction. It is effective to increase natriuresis by the action of vasodilatation, increased arterial associated with increased DFG (glomerular filtration rate) and sodium loading; It has a direct action of inhibiting the absorption of sodium in the proximal tube and the medullary tubular collector. It has an inhibitory effect on the release of renin, $\mathrm{ADH}$ (antidiuretic hormone) and aldosterone.

Prostaglandins have vasodilatory renal action and induce sodium and water removal. They increase sodium excretion by increasing the amount of filtered sodium and all that increases water excretion by antagonizing $\mathrm{ADH}$.

The sympathetic nervous system, the reninangiotensin-aldosterone system, the atrial natriuretic peptide and vasopressin are the four main system regulators that adapt their activity in response to changes in body fluid volume.

In this sense, it is important to know the pathophysiology of the various human processes that induce the retention or release of sodium and water. The 
sympathetic nervous system, the renin-angiotensinaldosterone system, the atrial natriuretic peptide and vasopressin are the four main system regulators that adapt their activity in response to changes in body fluid volume.

Maintaining the decrease in extracellular salt volume and water (much) leads to excessive consumption of intracellular water reserves.

The volume of sodium and extracellular water changes and the decrease of interstitial fluid volume, which is partly responsible for the elasticity and firmness of the skin, can strongly influence the mechanical and physiological functions of hydrophilic biomaterials.

A biomimetic/physiological approach has been pursued in the design of hybrid hybrid hybrid hybrid materials for the biomechanical stimulation and potentiation of bone mineralization and bone ossification.

Polymer (pHEMA) filled with nano silicon particles (5\% by volume). This material swells (approximately $14 \%$ linear) in the presence of an aqueous physiological solution (when in an aqueous biological environment), raising up to $40-45 \%$ by weight of water (depending on the water due to the physiological external environment) rigid at soft and rubber. The mechanical behavior of the proposed hybrid materials is comparable to that of the bone when it is vitreous and cartilage (ligaments) when it is rubber after swelling.

The use of mechanically-compatible hybrid hydrogels as scaffolding materials is expected to increase prosthetic adaptation mechanisms that introduce active interfaces that improve biomimetic implantation while reproducing the biomechanical functions of cartilage and ligaments. Adapted bone properties could benefit from the use of biomimetic biomaterials (biomechanical and bioactive compatible) coupled with new dentures.

According to the Private Health Research Laboratory, hypertension is the most dangerous disease in the $21 \mathrm{st}$ century. It sheds more people than cancer, AIDS, hepatitis, diabetes and tobacco taken together!

List of pathologies associated with high blood pressure when the disease is not cured on time.

Stage 1: At first, blood pressure increases occasionally, but at the same time, the first symptoms of hypertension are already present:

- headache

- Sleep disorder

- feeling tired

- palpitations

- $\quad$ ringing in the ears

- feeling unmotivated by anxiety

- shaking

- $\quad$ irrationality without reason

As a rule, patients do not hurry to go to the doctor, while the dishes and the heart begin to destroy:
Stage 2: The tension is growing more often and rarely returns to normal values. The patient may experience severe eye pressure, memory disturbances, swelling, abnormal working capacity, atherosclerosis and decreased vision. These symptoms indicate that the disease has gone too far. If the necessary steps are not taken at this stage, the person will completely waste their health.

Stage 3: There are irreversible processes. Blood flow disturbances and high blood pressure lead to the occurrence of many associated diseases: nephrosclerosis, renal failure, blindness, angina pectoris, diabetes mellitus, Alzheimer's disease, etc.

Stage 4: The blood vessels are so thin that internal pressure is ruptured at high pressure. If a bowel breaks out of the muscle, a heart attack occurs in the brain - stroke. Even if he does not die, he will remain invalid all his life.

Treatments for lowering blood pressure are multiple, with a very high diversity depending on the patient, the doctor, the situation. However, it may be generalized as a preventive, or adjuvant, use of dietary supplements containing vitamin $\mathrm{C}$. It can be taken naturally from cabbage, grapes, citrus, berries, tomatoes, onions, broccoli, strawberries, but it is often necessary daily synthetic supplements to be also consumed as needed.

As adjuvant treatments, acupuncture can also be used, or more pleasant and simpler, the homeopathy well applied by an experienced specialist.

Regular cleaning of blood vessels of depositions that take place inside them also has the beneficial effect of prolonging life as well as installing well-being on the applicant patient.

But this is just the first step in the anti-aging measures to be taken.

The highly circulating system needs permanent maintenance. Self-maintenance is done through various physiological mechanisms tightly linked to each other, including the lymphatic, digestive, renal, lung, nervous, glandular system ... It is not possible to completely separate the physiology of a system from the other adjacent systems because they all work synergistically, being permanently controlled by the central and peripheral nervous system.

Treatments for lowering blood pressure are multiple, with a very high diversity depending on the patient, the doctor, the situation. However, it may be generalized as a preventive, or adjuvant, use of dietary supplements containing vitamin $\mathrm{C}$. It can be taken naturally from cabbage, grapes, citrus, berries, tomatoes, onions, broccoli, strawberries, but it is often necessary daily synthetic supplements to be also consumed as needed.

As adjuvant treatments, acupuncture can also be used, or more pleasant and simpler, the homeopathy well applied by an experienced specialist.

Regular cleaning of blood vessels of depositions that take place inside them also has the beneficial effect of 
prolonging life as well as installing well-being on the applicant patient.

But this is just the first step in the anti-aging measures to be taken.

Because we live in times when we travel often and have a lot to do, dietary supplements are recommended for the body to function properly (and never get sick), supplements that people need such as vitamin $\mathrm{C}$, arginine (which is processed). Later in the body in nitric oxide), often and calcium is needed, vitamin D3 (today is considered a hormone) and vitamin K2. All three, vitamins $\mathrm{C}$, D3 and $\mathrm{K} 2$ contribute, among other things, to maintaining proper blood pressure, reducing it when it tends to jump.

\section{Acknowledgement}

This text was acknowledged and appreciated by Assoc. Pro. Taher M. Abu-Lebdeh, North Carolina A and T State Univesity, United States, Muftah H. El-Naas PhD MCIC FICCE QAFCO Chair Professor in Chemical Process Engineering Gas Processing Center College of Engineering Qatar University, Professor Guanying Chen Harbin Institute of Technology \& SUNY Buffalo China.

\section{Funding Information}

This research has been funded by Italian Ministry of University and Research project FIRB Future in Research 2008 project RBFR08T83J.

\section{Author's Contributions}

All the authors contributed equally to prepare, develop and carry out this manuscript.

\section{Ethics}

This article is original and contains unpublished material. Authors declare that are not ethical issues and no conflict of interest that may arise after the publication of this manuscript.

\section{References}

Abdul-Razzak, K., K. Alzoubi, S. Abdo and W. Hananeh, 2012. High-dose vitamin C: Does it exacerbate the effect of psychosocial stress on liver? Biochemical and histological study. Experim. Toxicol. Pathol., 64: 367-371.

DOI: $10.1016 /$ j.etp.2010.09.011

Ahmed, E., H. Omar, S. Elghaffar, S. Ragb and A. Nasser, 2011. The antioxidant activity of Vitamin C, DPPD and 1-cysteine against Cisplatin-induced testicular oxidative damage in rats. Food Chem. Toxicol., 49: 1115-1121. DOI: $10.1016 /$ j.fct.2011.02.002
Ajith, T.A., G. Abhishek, D. Roshny and N.P. Sudheesh, 2009. Co-supplementation of single and multi doses of vitamins $\mathrm{C}$ and $\mathrm{E}$ ameliorates cisplatin-induced acute renal failure in mice. Experim. Toxicol. Pathol., 61: 565-571.

DOI: $10.1016 /$ j.etp.2008.12.002

Alexander, C.A. and L. Wang, 2018. Healthcare driven by big data analytics. Am. J. Eng. Applied Sci., 11: 1154-1163. DOI: 10.3844/ajeassp.2018.1154.1163

Aljohani, A. and S. Desai, 2018. 3D printing of porous scaffolds for medical applications. Am. J. Eng. Applied Sci., 11: 1076-1085.

DOI: 10.3844/ajeassp.2018.1076.1085

Annunziata, M., L. Guida, L. Perillo, R. Aversa and I. Passaro et al., 2008. Biological response of human bone marrow stromal cells to sandblasted titanium nitride-coated implant surfaces. J. Mater. Sci. Mater. Med., 19: 3585-3591.

DOI: $10.1007 / \mathrm{s} 10856-008-3514-2$.

Annunziata, M., R. Aversa, A. Apicella, A. Annunziata and D. Apicella et al., 2006. In vitro biological response to a light-cured composite when used for cementation of composite inlays. Dental Materials, 22: 1081-1085.

DOI: 10.1016/J.DENTAL.2005.08.009

Apicella, A. and H.B. Hopfenberg, 1982. Water-swelling behavior of an ethylene-vinyl alcohol copolymer in the presence of sorbed sodium chloride. J. Applied Polymer Sci., 27: 1139-1148.

DOI: 10.1002/app.1982.070270404

Apicella, A., B. Cappello, M.A. Del Nobile, M.I. La Rotonda and G. Mensitieri et al., 1993. Poly(Ethylene oxide) (PEO) and different molecular weight PEO blends monolithic devices for drug release. Biomaterials, 142: 83-90.

DOI: 10.1016/0142-9612(93)90215-N

Apicella, A., R. Aversa and FIT. Petrescu, 2018a. Hybrid Ceramo-Polymeric Nano-Diamond Composites. Am. J. Eng. Applied Sci., 11: 766-782. DOI: 10.3844/ajeassp.2018.766.782

Apicella, A., R. Aversa and F.I.T. Petrescu, $2018 \mathrm{~b}$. Biomechanically Inspired Machines, Driven by Muscle Like Acting NiTi Alloys. Am. J. Eng. Applied Sci., 11: 809-829. DOI: 10.3844/ajeassp.2018.809.829

Apicella, A., R. Aversa, F. Tamburrino and FIT. Petrescu, 2018c. About the Internal Structure of a Bone and its Functional Role. Am. J. Eng. Applied Sci., 11: 914-931.

DOI: 10.3844/ajeassp.2018.914.931

Apicella, D., M. Veltri, P. Balleri, A. Apicella and M. Ferrari, 2011. Influence of abutment material on the fracture strength and failure modes of abutmentfixture assemblies when loaded in a bio-faithful simulation. Clin. Oral Implants Res., 22: 182-188. DOI: 10.1111/j.1600-0501.2010.01979.x 
Apicella, D., R. Aversa, E. Ferro, Ianniello, D. Ianniello and A. Apicella, 2010. The importance of cortical bone orthotropicity, maximum stiffness direction and thickness on the reliability of mandible numerical models. J. Biomed. Mater. Res. Part B Applied Biomater., 93: 150-163.

DOI: $10.1002 /$ jbm.b.31569

Apicella, D., R. Aversa, M. Tatullo, M. Simeone and S. Sayed et al., 2015a. Direct restoration modalities of fractured central maxillary incisors: A multi-levels validated finite elements analysis with in vivo strain measurements. Dental Mater., 31: e289-e305.

DOI: $10.1016 /$ j.dental.2015.09.016

Apicella, D., R. Aversa, M. Tatullo, M. Simeone and S. Sayed et al., 2015b. Direct restoration modalities of fractured central maxillary incisors: A multi-levels validated finite elements analysis with in vivo strain measurements. Dental Materials, 31: e289-e305, DOI: 10.1016/j.dental.2015.09.016

Armah, S.K., 2018. Stress analysis of an artificial human elbow joint: Application of finite element analysis. Am. J. Eng. Applied Sci., 11: 1-18.

DOI: 10.3844/ajeassp.2018.1.18

Atasayar, S., H. Gürer-Orhan, B. Gürel, G. Girgin and H. Özgünes, 2009. Preventive effect of aminoguanidine compared to vitamin $\mathrm{E}$ and $\mathrm{C}$ on cisplatin-induced nephrotoxicity in rats. Experim. Toxicol. Pathol., 61: 23-32. DOI: 10.1016/j.etp.2008.04.016

Aversa, R., D. Apicella, L. Perillo, R. Sorrentino and F. Zarone et al., 2009. Non-linear elastic threedimensional finite element analysis on the effect of endocrown material rigidity on alveolar bone remodeling process. Dental Materials, 25: 678-690: DOI: $10.1016 /$ j.dental.2008.10.015

Aversa, R., D. Parcesepe, R.V. Petrescu, G. Chen and F.I.T. Petrescu et al., 2016b. Glassy amorphous metal injection molded induced morphological defects. Am. J. Applied Sci., 13: 1476-1482.

Aversa, R., E.M. Buzea, R.V. Petrescu, A. Apicella and M. Neacsa et al., 2016e. Present a mechatronic system having able to determine the concentration of carotenoids. Am. J. Eng. Applied Sci., 9: 1106-1111.

Aversa, R., F. Tamburrino, R.V. Petrescu, F.I.T. Petrescu and M. Artur et al., 2016d. Biomechanically inspired shape memory effect machines driven by Muscle like Acting NiTi Alloys. Am. J. Applied Sci., 13: 1264-1271.

Aversa, R., F.I.T. Petrescu, R.V. Petrescu and A. Apicella, 2016a. Biomimetic FEA bone modeling for customized hybrid biological prostheses development. Am. J. Applied Sci., 13: 1060-1067. DOI: 10.3844/ajassp.2016.1060.1067

Aversa, R., F.I.T. Petrescu, R.V. Petrescu and A. Apicella, 2016o. Flexible stem trabecular prostheses. Am. J. Eng. Applied Sci., 9: 1213-1221.
Aversa, R., R.V. Petrescu, A. Apicella and F.I.T. Petrescu, 2016i. Mitochondria are naturally micro robots - a review. Am. J. Eng. Applied Sci., 9: 991-1002.

Aversa, R., R.V. Petrescu, A. Apicella and F.I.T. Petrescu, 2016j. We are addicted to Vitamins C and EA review. Am. J. Eng. Applied Sci., 9: 1003-1018.

Aversa, R., R.V. Petrescu, A. Apicella and F.I.T. Petrescu, 2016k. Physiologic human fluids and swelling behavior of hydrophilic biocompatible hybrid ceramo-polymeric materials. Am. J. Eng. Applied Sci., 9: 962-972.

Aversa, R., R.V. Petrescu, A. Apicella and F.I.T. Petrescu, 20161. One can slow down the aging through antioxidants. Am. J. Eng. Applied Sci., 9: 1112-1126.

Aversa, R., R.V. Petrescu, A. Apicella and F.I.T. Petrescu, 2016m. About Homeopathy or Similia Similibus Curentur. Am. J. Eng. Applied Sci., 9: 1164-1172.

Aversa, R., R.V. Petrescu, A. Apicella and F.I.T. Petrescu, 2016n. The basic elements of life's. Am. J. Eng. Applied Sci. 9: 1189-1197.

Aversa, R., R.V. Petrescu, A. Apicella and F.I.T. Petrescu, 2017. Modern transportation and photovoltaic energy for urban ecotourism. Transylvanian Review Administrative Sciences Special Issue. DOI: 10.24193/tras.SI2017.1

Aversa, R., R.V. Petrescu, F.I.T. Petrescu and A. Apicella, 2016c. Smart-factory: Optimization and process control of composite centrifuged pipes. Am. J. Applied Sci., 13: 1330-1341.

Aversa, R., R.V. Petrescu, F.I.T. Petrescu and A. Apicella, 2016h. Biomimetic and evolutionary design driven innovation in sustainable products development. Am. J. Eng. Applied Sci., 9: 1027-1036.

Aversa, R., R.V. Petrescu, R. Sorrentino, F.I.T. Petrescu and A. Apicella, 2016f. Hybrid ceramo-polymeric nanocomposite for biomimetic scaffolds design and preparation. Am. J. Eng. Applied Sci., 9: 1096-1105.

Aversa, R., V. Perrotta, R.V. Petrescu, C. Misiano and F.I.T. Petrescu et al., 2016g. From structural colors to super-hydrophobicity and achromatic transparent protective coatings: Ion plating plasma assisted $\mathrm{TiO} 2$ and $\mathrm{SiO} 2$ nano-film deposition. Am. J. Eng. Applied Sci., 9: 1037-1045.

Babaev, V.R., L. Li, S. Shah, S. Fazio and M.F. Linton et al., 2010. Combined vitamin $\mathrm{C}$ and vitamin $\mathrm{E}$ deficiency worsens early atherosclerosis in apolipoprotein E-Deficient mice. Arteriosclerosis Thrombosis Vascular Biol., 30: 1751-1757. DOI: 10.1161/ATVBAHA.110.209502

Badziag, P., W.S. Verwoerd, W.P. Ellis and N.R. Greiner, 1990, Nanometre-sized diamonds are more stable than graphite. Nature, 343: 244-245. DOI: $10.1038 / 343244 a 0$ 
Barnard, A.S. and M. Sternberg, 2007. Crystallinity and surface electrostatics of diamond nanocrystals. J. Mater. Chem., 17: 4811-4819. DOI: 10.1039/b710189a

Barnard, A.S., S.P. Russo and I.K. Snook, 2003. Structural relaxation and relative stability of nanodiamond morphologies. Diamond Relat. Mater., 12: $1867-1872$.

DOI: $10.1016 / \mathrm{S} 0925-9635(03) 00275-9$

Beaupre, G.S. and W.C. Hayes, 1985. Finite element analysis of a three dimensional open-celled model for trabecular bone. J. Biomech. Eng. 107: 249-56, PMID: 4046566

Bonfield, W., M.D. Grynpas, A.E. Tully, J. Bowman and J. Abram, 1981. Hydroxyapatite reinforced polyethylene-a mechanically compatible implant material for bone replacement. Biomaterials, 2: 185186. DOI: $10.1016 / 0142-9612(81) 90050-8$

Bryan, N.S., K. Bian and F. Murad, 2009. Discovery of the nitric oxide signaling pathway and targets for drug development. Front. Biosci. (LandmarkEd). 14: 1-18.

Buzea, E., F.1. Petrescu, L. Nanut, C. Nan and M. Neacsa, 2015. Mechatronic system to determine the concentration of carotenoids, analele Univers. Craiova Biologie Horticultura Tehn. Prel. Prod. Agr. Ing. Med., 20: 371-376.

Čepelak, I., S. Dodig and O. Čulić, 2013. Magnesiummore than a common cation. Med. Sci., 39: 47-68.

Chang, Y.R., J.H. Hsu, K. Chen and W. Fann, 2008. Mass production and dynamic imaging of fluorescent nanodiamonds. Nature Nanotech., 3: 284-288. DOI: 10.1038/nnano.2008.99

Chen, Q., C. Zhu and G.A. Thouas, 2012. Progress and challenges in biomaterials used for bone tissue engineering: Bioactive glasses and elastomeric composites. Progress. Biomater., 1: 1-22. DOI: 10.1186/2194-0517-1-2

Choudhury, A. and C.M. Greene, 2018. Identification of cancer: Mesothelioma's disease using logistic regression and association rule. Am. J. Eng. Applied Sci.

Choudhury, A., 2018. Evaluating patient readmission risk: A predictive analytics approach. Am. J. Eng. Applied Sci.

Chow, E.K., X.Q. Zhang, M. Chen, R. Lam and E. Robinson et al., 2010. Nanodiamond therapeutic delivery agents mediate enhanced chemoresistant tumor treatment. Sci. Transl. Med., 3: 73ra2173ra21. DOI: 10.1126/scitranslmed.3001713

Comerun, H.U., 1986. Six-year results with a microporouscoated metal hip prosthesis, Clin. Orthop.

Cormack, A.N. and A. Tilocca, 2012. Structure and biological activity of glasses and ceramics. Philos. Trans. Math. Phys. Eng. Sci., 370: 1271-1280. DOI: 10.1098/rsta.2011.0371
Covic, M., A. Covic, P.G. Tatomir and L. Segall, 2007. Manual de Nefrologie. 1st Edn., Polirom Publisher, pp: 448.

Davis, P.A., S.J. Huang, L. Nicolais and L. Ambrosio, 1991. Modified PHEMA Hydrogels. In: Szycher M, editor. High Performance Biomaterials. Lancaster, PA, USA: Technonic.

Derbyshire, E.R. and M.A. Marletta, 2009. Biochemistry of soluble guanylate cyclase. Handb Exp. Pharmacol. 191: 17-31.

El-Gendy, K.S., N.M. Aly, F.H. Mahmoud, A. Kenawy and A.K. El-Sebae, 2009. The role of vitamin C as antioxidant in protection of oxidative stress induced by imidacloprid. Food Chem. Toxicol., 48: 215-221.

Enstrom, J., 2014. Food and you: Feeding the world with modern agricultural biotechnology. Am. Council Science Health.

Eroy-Reveles, A.A. and P.K. Mascharak, 2009. Nitric oxide-donating materials and their potential in pharmacological applications for site-specific nitric oxide delivery. Future Med. Chem., 1: 1497-1507.

Filmon, R., F. Grizon, M.F. Baslie and D. Chappard, 2002. Effects of negatively charged groups (carboxymethyl) on the calcification of poly(2hydroxyethylmethacrylate). Biomaterials, 23: 3053-9.

Frost, H.M., 1964. Mathematical elements of lamellar bone remodeling. Springfield: Charles C Thomas, pp: 22-25.

Frost, H.M., 1990. Structural Adaptations to Mechanical Usage (SATMU). 2. Redifining Wolff's law: the bone remodelling problem. Anat. Rec., 226: 414-22.

Frost, H.M., 1994. Wolff's law and bone's structural adaptations to mechanical usage: An overview for clinicians. Angle Orthod., 64: 175-88.

Frost, H.M., 2003 update of bone physiology and Wolff's law for clinicians. Angle Orthod., 74: 3-15.

Gorustovich, A.A., J.A. Roether and A.R. Boccaccini, 2010. Effect of bioactive glasses on angiogenesis: A review of in vitro and in vivo evidences. Tissue Eng. Part B Rev., 16: 199-207. DOI: $10.1089 /$ ten.TEB.2009.0416

Gramanzini, M., S. Gargiulo, F. Zarone, R. Megna and A. Apicella, 2016. Combined microcomputed tomography, biomechanical and histomorphometric analysis of the peri-implant bone: A pilot study in minipig model. Dental Materials, 32: 794-806. DOI: 10.1016/j.dental.2016.03.025

Greiner, N.R., D.S. Phillips, J.D. Johnson and F. Volk, 1988. Diamonds in detonation soot. Nature, 333: 440-442. DOI: 10.1038/333440a0

Ha, H.L., H.J. Shin, M.A. Feitelson and D.Y. Yu, 2010. Oxidative stress and antioxidants in hepatic pathogenesis. World J. Gastroenterol., 16: 6035-6043.

Halpin, J.C. and J.L. Kardos, 1976. Halpin-Tsai equations: A review. Polymer Eng. Sci., 16: 344-352. 
Hansen, S.N., P. Tveden-Nyborg, J. Lykkesfeldt, 2014. Does vitamin $\mathrm{C}$ deficiency affect cognitive development and function? Nutrients, 6: 3818-3846.

Heinemann, S., C. Heinemann, S. Wenisch, V. Alt and H. Worch et al., 2013. Calcium phosphate phases integrated in silica/collagen nanocomposite xerogels enhance the bioactivity and ultimately manipulate the osteoblast/osteoclast ratio in a human co-culture model. Acta Biomaterialia, 9: 4878-4888.

DOI: $10.1016 /$ j.actbio.2012.10.010

Hench, L.L. and I. Thompson, 2010. Twenty-first century challenges for biomaterials. J. Royal Society Interface, 7: S379-S391.

DOI: 10.1098/rsif.2010.0151.focus

Hench, L.L. and J. Wilson, 1993. An introduction to bioceramics. World Sci., 1: 396-396. DOI: $10.1142 / 2028$

Hench, L.L. and J.M. Polak, 2002. Third-generation biomedical materials. Science, 295: 1014-1017. DOI: $10.1126 /$ science. 1067404

Hickey, S. and H. Roberts, 2007. The Cancer Breakthrough, ISBN-10: 9781430323006, pp: 96.

Hill, B.G., B.P. Dranka and S.M. Bailey, 2010. What part of NO don't you understand? Some answers to the cardinal questions in nitric oxide biology. J. Biol. Chem., 285: 19699-704.

Holley, R.H., H.B. Hopfenberg and V. Stannett, 1970. Anomalous transport of hydrocarbons in polystyrene. Polymer Eng. Sci., 10: 376-382. DOI: $10.1002 /$ pen.760100612

Hoppe, A., N.S. Güldal and A.R. Boccaccini, 2011. A review of the biological response to ionic dissolution products from bioactive glasses and glass-ceramics. Biomaterials, 32: 2757-2774.

DOI: 10.1016/j.biomaterials.2011.01.004

Huiskes, R., H. Weinans, H.J. Grootenboer, M. Dalstra and B. Fudula et al., 1987. Adaptive bone remodeling theory applied to prosthetic-design analysis. J. Biomech, 20: 1135-1150.

Hutmacher, D.W., 2000. Scaffolds in tissue engineering bone and cartilage. Biomaterials, 21: 2529-2543. DOI: 10.1016/S0142-9612(00)00121-6

Jarre, G., Y.J. Liang, P. Betz, D. Lang and A. Krueger, 2011. Playing the surface game-Diels-Alder reactions on diamond nanoparticles. Chem. Commun., 47: 544-546. DOI: 10.1039/C0CC02931A

Jones, J.R. and A.G. Clare, 2012. Bio-Glasses. An Introduction. 1st Edn., Wiley, Chichester, ISBN-10: 1118346475, pp: 320.

Julien, M., D. Magne, M. Masson, M. Rolli-Derkinderen and O. Chassande et al., 2007. Phosphate stimulates matrix Gla protein expression in chondrocytes through the extracellular signal regulated Kinase signaling pathway. Endocrinology, 148: 530-537. DOI: 10.1210/en.2006-0763
Kabra, B., S.H. Gehrke, S.T. Hwang and W. Ritschel, 1991. Modification of the dynamic swelling behaviour of pHEMA. J. Applied Polym. Sci., 42: 2409-2416. DOI: 10.1002/app.1991.070420906

Karageorgiou, V. and D. Kaplan, 2005. Porosity of 3D biomaterial scaffolds and osteogenesis. Biomaterials, 26: 5474-5491.

DOI: $10.1016 /$ j.biomaterials.2005.02.002

Kim, H.W., J.C. Knowles and H.E. Kim, 2004. Development of hydroxyapatite bone scaffold for controlled drug release via poly( $\epsilon$-caprolactone) and hydroxyapatite hybrid coatings. J. Biomed. Mater. Res. Part B: Applied Biomater., 70: 240-249.

DOI: $10.1002 / j b m . b .30038$

Krueger, A., J. Stegk, Y.J. Liang, L. Lu and G.B. Jarre, 2008. Nanodiamond: Simple and efficient functionalization of detonation diamond. $\mathrm{E}$ Langmuir, 24: 4200-4204. DOI: 10.1021/la703482v

Krueger, A., Y.J. Liang, G. Jarre and J. Stegk, 2006, Surface functionalisation of detonation diamond suitable for biological applications. J. Mater. Chem., 16: 2322-2328. DOI: 10.1039/B601325B

Kunutsor, S., S. Kurl, F. Zaccardi and J. Laukkanen, 2016. Baseline and long-term fibrinogen levels and risk of sudden cardiac death: A new prospective study and meta-analysis. Atherosclerosis, 245: 171-180.

Lai, L. and A.S. Barnard, 2011a. Modeling the thermostability of surface functionalisation by oxygen, hydroxyl and water on nanodiamonds. Nanoscale, 3: 2566-2575. DOI: 10.1039/c1nr10108k

Lai, L. and A.S. Barnard, 2011b. Stability of nanodiamond surfaces exposed to $\mathrm{N}, \mathrm{NH}$ and $\mathrm{NH} 2$. J. Phys. Chem. C, 115: 6218-6228.

DOI: $10.1021 /$ jp1111026

Lee, Y.I., T.M. Dawson and V.L. Dawson, 2009. Role of $\mathrm{NO}$ in Neurodegeneration. In: Intercellular Communication in the Nervous System, Malenka, R. (Ed.), Academic Press, Elsevier. Pp: 690-696.

Mano, J.F., R.A. Sousa, L.F. Boesel, N.M. Neves and R.L. Reis, 2004. Bioinert, biodegradable and injectable polymeric matrix composites for hard tissue replacement: State of the art and recent developments. Composi. Sci. Technol., 64: 789-817. DOI: 10.1016/j.compscitech.2003.09.001

Marquetti, I. and S. Desai, 2018. Adsorption Behavior of Bone Morphogenetic Protein-2 on a Graphite Substrate for Biomedical Applications. Am. J. Eng. Applied Sci., 11: 1037-1044. DOI: 10.3844/ajeassp.2018.1037.1044

Marrelli, M., G. Falisi, A. Apicella, D. Apicella and M. Amantea et al., 2015. Behaviour of dental pulp stem cells on different types of innovative mesoporous and nanoporous silicon scaffolds with different functionalizations of the surfaces. J. Biol. Regulators Homeostatic Agents, 9: 991-997. PMID: 26753666 
Martin, R.B., D.B. Burr and N.A. Sharkey, 1998. Skeletal Tissue Mechanics. 1st Edn., Springer, New York, ISBN-10: 0387984747, pp: 392.

Massion, P.B., M. Pelat and C. Belge, 2005. Regulation of the mammalian heart function by nitric oxide. Comp. Biochem. Physiol a Mol Integr Physiol., 142: 144-150.

Miller, M.R. and I.L. Megson, 2007. Recent developments in nitric oxide donor drugs. Br. J. Pharmacol., 151: 305-321.

Mohan, N., C.S. Chen, H.H. Hsieh, Y.C. Wu and H.C. Chang, 2010. In vivo imaging and toxicity assessments of fluorescent nanodiamonds in Caenorhabditis elegans. Nano Lett., 10: 3692-3699. DOI: $10.1021 / \mathrm{nl} 1021909$

Montheard, J.P., M. Chatzopoulos and D. Chappard 1992. 2-hydroxyethylmethacrylate HEMA; chemical properties and applications in biomedical fields. J. Macromol. Sci. Macromol. Rev., 32: 1-34. DOI: 10.1080/15321799208018377

Morales-Hernandez, D.G., D.C. Genetos, D.M. Working, K.C. Murphy and J.K. Leich, 2012. Ceramic identity contributes to mechanical properties and osteoblast behavior on macroporous composite scaffolds. J. Funct. Biomat., 23: 382-397. DOI: $10.3390 /$ jfb3020382

Mouriño, V., J.P. Cattalini and A.R. Boccaccini, 2012. Metallic ions as therapeutic agents in tissue engineering scaffolds: An overview of their biological applications and strategies for new developments. J. Royal Society Interface, 9: 401419. DOI: 10.1098/rsif.2011.0611

Nicolais, L., A. Apicella and C. de Notaristefano, 1984. Time-temperature superposition of n-hexane sorption in polystyrene. J. Membrane Sci., 18: 187-196. DOI: 10.1016/S0376-7388(00)85033-4

Osswald, S., G. Yushin, V. Mochalin, S.O. Kucheyev and Y. Gogotsi, 2006. Control of sp2/sp3 carbon ratio and surface chemistry of nanodiamond powders by selective oxidation in air. J. Am. Chem. Soc., 128: 11635-11642. DOI: 10.1021/ja063303n

Ozawa, M., M. Inaguma, M. Takahashi, F. Kataoka and A. Krüger et al., 2007. Preparation and behavior of brownish, clear nanodiamond colloids. Adv. Mater., 19: 1201-1206. DOI: 10.1002/adma.200601452

Parfitt, A.M., 1983. The Physiological and Clinical Significance of Bone Histomorphometric Data. In: Bone Histomorphometry: Techniques and Interpretation, Recker, R.R. (Ed.), CRC Press, Boca Raton, pp: 143-223.

Parfitt, A.M., 1994. Osteonal and hemi-osteonal remodeling: The spatial and temporal framework for signal traffic in adult human bone. J. Cell Biochem., 55: 273-286. DOI: $10.1002 /$ jcb. 240550303
Peluso, G., O. Petillo, J.M. Anderson, M. Ambrosio and L. Nicolais et al., 1997. The differential effects of poly(2-hydroxyethylmethacrylate) and poly(2hydroxyethylmethacrylate)/poly(caprolactone) polymers on cell proliferation and collagen synthesis by human lung fibroblasts. J. Biomed. Mater. Res., 34: 327-336. DOI: 10.1002/(SICI)10974636(19970305)34:3<327::AID-JBM7>3.0.CO;2-M

Perillo, L., R. Sorrentino, D. Apicella, A. Quaranta and E.D. Gherlone et al., 2010. Nonlinear visco-elastic finite element analysis of porcelain veneers: A submodelling approach to strain and stress distributions in adhesive and resin cement. $J$. Adhesive Dentistry, 12: 403-413.

Petrescu, F.I.T. and K.J. Calautit, 2016a. About Nano Fusion and Dynamic Fusion, Am. J. Applied Sci., 13: 261-266.

Petrescu, F.I.T. and K.J. Calautit, 2016b. About the Light Dimensions. Am. J. Applied Sci. 13: 321-325.

Petrescu, F.I.T. and R.V. Petrescu, 2017. The computer algorithm for machine equations of classical distribution. J Materials Eng. Structures, 4: 193-209.

Petrescu, F.I.T. and R.V. Petrescu, 2018. Inverse kinematics to a Stewart platform. J. Materials Eng. Structures, 5: 111-122.

Petrescu, F.I.T. and R.V. Petrescu, 2019. Nuclear hydrogen structure and dimensions. Int. J. Hydrogen Energy, 44: 10833-10837.

DOI: $10.1016 /$ j.ijhydene.2019.02.140

Petrescu, F.I.T., 2019. About the nuclear particles' structure and dimensions. Comp. Part. Mech., 6: 191-194. DOI: 10.1007/s40571-018-0206-7

Petrescu, F.I.T., A. Apicella, R. Aversa, R.V. Petrescu and J.K. Calautit et al., 2016a. Something about the Mechanical Moment of Inertia. Am. J. Applied Sci., 13: 1085-1090.

Petrescu, F.I.T., A. Apicella, R.V. Petrescu, S.P. Kozaitis and R.B. Bucinell et al., 2016d. Environmental protection through nuclear energy. Am. J. Applied Sci., 13: 941-946.

Petrescu, F.L., E. Buzea, L. Nănuţ, M. Neacşa and C. Nan, 2015. The role of antioxidants in slowing aging of skin in a human, Analele Univers. Craiova Biologie Horticultura Tehn. Prel. Prod. Agr. Ing. Med., 20: 567-574.

Petrescu, R.V., R. Aversa, A. Apicella and F.I.T. Petrescu, 2016e. Future medicine services robotics. Am. J. Eng. Applied Sci., 9: 1062-1087.

Petrescu, R.V., R. Aversa, A. Apicella, F. Berto and S. Li et al., 2016c. Ecosphere protection through green energy. Am. J. Applied Sci., 13: 1027-1032.

Petrescu, R.V., R. Aversa, A. Apicella, S. Li and G. Chen et al., 2016b. Something about Electron Dimension. Am. J. Applied Sci., 13: 1272-1276. 
Prashantha, K., K. Vasanth Kumar Pai, B.S. Sherigara and S. Prasannakumar, 2001. Interpenetrating polymer networks based on polyol modified castor oil polyurethane and poly-(2-hydroxyethylmethacrylate): Synthesis, chemical, mechanical thermal properties. Bull. Mater Sci., 24: 535-8.

I. Huk: Nitric oxide is the most important molecule for health. https://www.csid.ro/health/sanatate/prof-drihor-huk-oxidul-nitric-este-cea-mai-importantamolecula-pentru-sanatate-17219259

Rath, M. and L. Pauling, 1990. Hypothesis: lipoprotein(a) is a surrogate for ascorbate, Proc. Natl. Acad Sci. USA, 87: 6204-6207.

Rath, M., 2003. Why Animals Don't Get Heart Attacks. . . but People Do!. 4th Edn., MR Publishing, Inc., Fremont, CA, USA, ISBN-13: 978-0-9679546-8-4, pp: 319.

Ravnskov, U., 2009. Fat and Cholesterol are Good for You, Publisher: GB Publishing, English, ISBN-13: 978-9197555388, pp: 244.

Reilly, D. and A.H. Burstein, 1974. The mechanical properties of cortical bone. J. Bone Joint Surgery, 56A: 1001-1021.

Reilly, D. and A.H. Burstein, 1975. The elastic and ultimate properties of compact bone tissue. J. Biomechanics, 8: 393-405.

DOI: $10.1016 / 0021-9290(75) 90075-5$

Schiraldi, C., A. D'Agostino, A. Oliva, F. Flamma and A. De Rosa et al., 2004. Development of hybridmaterials based on hydroxyethylmethacrylate as supports for improving cell adhesion and proliferation. Biomaterials, 25: 3645-3653.

DOI: $10.1016 /$ j.biomaterials.2003.10.059

Schrand, A.M., J. Johnson, L. Dai and E. Ōsawa, 2009a. Cytotoxicity and Genotoxicity of Carbon Nanomaterials. In: Safety of Nanoparticles: From Manufacturing to Medical Applications, Nanostructure Science and Technology. Webster, T.J. (Ed.), ISSN-10: 1571-5744, pp: 159-187.

Schrand, A.M., S.A.C. Hens and O.A. Shenderova, 2009b. Nanodiamond particles: Properties and perspectives for bioapplications. Crit. Rev. Solid State Mater. Sci., 34: 18-74.

DOI: $10.1080 / 10408430902831987$

Schwartz-Dabney, C.L. and P.C. Dechow, 2003. Variation in cortical material properties throughout the human dentate mandible. Am. J. Phys. Anthropol., 120: 252-277. DOI: 10.1002/ajpa.10121

Shenderova, O., A. Koscheev, N. Zaripov, I. Petrov and Y. Skryabin et al., 2011. Surface chemistry and properties of ozone-purified detonation nanodiamonds. J. Phys. Chem. C, 115: 9827-9837. DOI: 10.1021/jp1102466

Shinde, U.A., A.A. Mehta and R.K. Goyal, 2000. Nitric Oxide: A molecule of the millennium. Indian J. Exp. Biol., 38: 201-10.
Sorrentino, R., D. Apicella, C. Riccio, E.D. Gherlone and F. Zarone et al., 2009. Nonlinear visco-elastic finite element analysis of different porcelain veneers configuration. J. Biomed. Mater. Res., 91: 727-736. DOI: 10.1002/jbm.b.31449

Sorrentino, R., R. Aversa, V. Ferro, T. Auriemma and F. Zarone et al., 2007. Three-dimensional finite element analysis of strain and stress distributions in endodontically treated maxillary central incisors restored with different post, core and crown materials. Dent Mater., 23: 983-993.

DOI: $10.1016 /$ j.dental.2006.08.006

Tamburrino, F., A. Apicella, R. Aversa and F.I.T. Petrescu, 2018. Advanced manufacturing for novel materials in industrial design applications. Am. J. Eng. Applied Sci., 11: 932-972.

DOI: 10.3844/ajeassp.2018.932.972

Taylor, D., J.G. Hazenberg and T.C. Lee, 2007. Living with cracks: Damage and repair in human bone. Nat. Mater., 6: 263-268. DOI: 10.1038/nmat1866

Töyräsa, J., T. Lyyra-Laitinena, M. Niinimäkib, R. Lindgrenc and M.T. Nieminenb et al., 2001. Estimation of the Young's modulus of articular cartilage using an arthroscopic indentation instrument and ultrasonic measurement of tissue thickness. J. Biomechan., 34: 251-256. DOI: 10.1016/S0021-9290(00)00189-5

Viecelli, J.A., S. Bastea, J.N. Glosli and F.H. Ree, 2001. Phase transformations of nanometer size carbon particles in shocked hydrocarbons and explosives. J. Chem. Phys., 115: 2730-2736.

DOI: $10.1063 / 1.1386418$

Webb, A.J., N. Patel and S. Loukogeorgakis, 2008. Acute blood pressure lowering, vasoprotective and antiplatelet properties of dietary nitrate via bioconversion to nitrite. Hypertens, 51: 784-90.

Wilk, J., G. Sanders, S. Marks, S.A. Paolicelli and M. DiCaprio et al., 2017. The Optimization of a Porous Ti6Al4V bone construct using additive manufacturing. Am. J. Eng. Applied Sci., 10: 13-19. DOI: 10.3844/ajeassp.2017.13.19

Willis, G.C., 1953. An experimental study of the intimal ground substance in atherosclerosis. Can Med. Assoc. J., 69: 17-22.

Willis, G.C., 1957. The reversibility of atherosclerosis. Can Med. Assoc. J., 77: 106-108.

Willis, G.C., A.W. Light and W.S. Gow, 1954. Serial Arteriography in Atherosclerosis in Human Beings. Can Med. Assoc J., 71: 562-568.

Wolff, J., 1892. Das Gesetz der Transformation der Knochen. Berlin: A Hirschwald.

Xiao, J., G. Ouyang, P. Liu, C.X. Wang and G.W. Yang, 2014. Reversible Nanodiamond-carbon onion phase transformations. Nano Letters, ACS Publications. DOI: $10.1021 / \mathrm{nl} 5014234$ 
Yuan, Y., X. Wang, G. Jia, J.H. Liu and T. Wang et al., 2010. Pulmonary toxicity and translocation of nanodiamonds in mice. Diamond Relat. Mater., 19: 291-299.

DOI: $10.1016 /$ j.diamond.2009.11.022

Zhang, Q., V.N. Mochalin, I. Neitzel, I.Y. Knoke and J. Han et al., 2011. Fluorescent PLLA-nanodiamond composites for bone tissue engineering. Biomaterials, 32: 87-94.

DOI: $10.1016 /$ j.biomaterials.2010.08.090

\section{Sources of Figures}

Fig.

1:

https://en.wikipedia.org/wiki/Circulatory_system\#/media /File:Circulatory_System_en.svg

Fig.

2:

https://en.wikipedia.org/wiki/Circulatory_system\#/media /File:Diagram_of_the_human_heart_(cropped).svg

Fig. 3: https://en.wikipedia.org/wiki/Circulatory_system\#/media /File:2119_Pulmonary_Circuit.jpg 